\title{
Impact of surface temperature biases on climate change projections of the South Pacific Convergence Zone
}

\author{
Dutheil Cyril ${ }^{1,{ }^{*}}$, Bador M. ${ }^{2}$, Lengaigne M. ${ }^{3}$, Lefèvre J. ${ }^{1}$, Jourdain N. C. ${ }^{4}$, Vialard J. ${ }^{3}$, Jullien Swen ${ }^{5}$, \\ Peltier A. ${ }^{6}$, Menkes C. ${ }^{1}$
}

1 IRD (Institut de Recherche pour le Développement)- Sorbonne Universités (UPMC, Université Paris 06)-CNRSMNHN- IPSL, LOCEAN Laboratory, IRD Nouméa BP A5, 98848 Nouméa, New Caledonia, France

${ }^{2}$ Climate Change Research Centre and ARC Centre of Excellence for Climate Extremes, School of BEES, University of New South Wales, Sydney, NSW, Australia

3 LOCEAN-IPSL, Sorbonne Universités, UPMC, Université Paris 06, CNRS-IRD-MNHN, Paris, France

4 University of Grenoble Alpes/CNRS/IRD/G-INP, IGE, Grenoble, France

${ }^{5}$ Ifremer, University of Brest, CNRS, IRD, Laboratoire d'Océanographie Physique et Spatiale (LOPS), IUEM, Plouzané, France

${ }^{6}$ Météo France, Nouméa, Nouvelle Calédonie, France

*Corresponding author : Cyril Dutheil, email address : cyril.dutheil@ird.fr

\begin{abstract}
:
The South Pacific Convergence Zone (SPCZ) is poorly represented in global coupled simulations from the Coupled Model Intercomparison Project Phase 5 (CMIP5), with trademark biases such as the tendency to form a "double Intertropical convergence zone" and an equatorial cold tongue that extends too far westward. Such biases limit our confidence in projections of the future climate change for this region. In this study, we use a downscaling strategy based on a regional atmospheric general circulation model that accurately captures the SPCZ present-day climatology and interannual variability. More specifically, we investigate the sensitivity of the projected rainfall response to either just correcting present-day CMIP5 Sea Surface Temperature (SST) biases or correcting projected SST changes using an emergent constraint approach. While the equatorial western Pacific projected rainfall increase is robust in our experiments and CMIP5, correcting the projected CMIP5 SST changes yields a considerably larger reduction $(\sim 25 \%)$ than in CMIP5 simulations $(\sim+3 \%)$ in the southwestern Pacific. Indeed, correcting the projected CMIP5 warming pattern yields stronger projected SST gradients, and more humidity convergence reduction under the SPCZ. Finally, our bias-corrected set of experiments yields an increase in equatorial rainfall and SPCZ variability in the future, but does not support the future increase in the frequency of zonal SPCZ events simulated by CMIP5 models. This study hence suggests that atmospheric downscaling studies should not only correct CMIP5 present-day SST biases but also projected SST changes to improve the reliability of their projections. Additional simulations with different physical parameterizations yield robust results.
\end{abstract}

Keywords : Regional climate models, South Pacific Convergence Zone, Precipitation, Sea Surface Temperature 
The South Pacific Convergence Zone (SPCZ) is the largest convective area of the Southern Hemisphere in austral summer (Kiladis et al. 1989; Fig. 1a) and plays a major role on the earth's climate (Vincent 1994; van der Wiel et al., 2016a). Climatological characteristics of the SPCZ have been related to the underlying sea surface temperature (SST) gradients (van der Wiel et al., 2016b). The SPCZ exhibits a diagonal orientation along a north-west/south-east axis, stretching from the Solomon Islands to the central subtropical Pacific (thick line in Figure 1a; Kiladis et al. 1989; Vincent 1994), which has been attributed to the equatorward propagation and the diagonal orientation of eastward propagating Rossby wave trains (Widlansky et al., 2011; Matthews, 2012; van der Wiel et al., 2015). The SPCZ is the main source of rainfall for a vast majority of South Pacific island nations, where local hydrological conditions are very sensitive to its displacements (e.g. Alexander et al. 2006; Gouriou and Delcroix 2002; Murphy et al. 2015). The location of this rain belt not only strongly constrains the regional hydrological cycle but is also the breeding ground of South Pacific tropical cyclones (Vincent et al. 2011). The SPCZ interannual variability hence affects the frequency of droughts, floods, and cyclones experienced by these vulnerable island countries (Vincent 1994; Alexander et al. 2006; Kirono et al. 2011; Vincent et al. 2011). These variations are strongly tied to the El Niño/Southern Oscillation (ENSO), the most energetic climate mode at interannual timescales (Timmermann et al., 2018). Moderate El Niño (resp. La Niña) events tend to induce a northeastward (resp. southwestward) displacement of the SPCZ (e.g. Folland 2002; JuilletLeclerc et al. 2006; Kidwell et al. 2016; Trenberth 1976; see also Fig. 4). This displacement is much more radical during extreme El Niño events (Santoso et al., 2017), such as in 1982-1983, 1997-1998 and 2015-2016, when the SPCZ undergoes an equatorward swing of up to ten degrees of latitude and collapses to a more zonally oriented structure (e.g. Vincent et al. 2011; Cai et al. 2012). This unusual SPCZ shift and re-orientation during extreme El Niños likely arise from the non-linear rainfall response to ENSO-related SST signals (Chung et al. 2014). These extreme events have outsized impacts relative to weaker El Niños, including massive drought, food shortage (Kirono et al. 2011) and a considerable reorganisation of cyclogenesis (Vincent et al. 2011), with an unusual occurrence of cyclones in French 70 Polynesia.

Global warming also has the potential to influence the SPCZ rainfall location, intensity or variability, which may severely impact the water resources of many South Pacific islands. The detection of such changes in observations remains uncertain because of the strong aliasing by natural decadal/multi-decadal variability over the past 40 years 
(Vecchi et al. 2008; Deser et al. 2010; Meng et al. 2012; Solomon and Newman, 2012; Tokinaga et al. 2012; McGree et

75 al. 2014). The assessment of the tropical Pacific response to global warming hence heavily relies on projections

76 performed with climate models from the Coupled Model Intercomparison Project (CMIP; Meehl et al. 2007; Taylor et

77 al. 2012). These projections for the late $21^{\text {st }}$ century generally depict a robust tropical Pacific SST response to

78 greenhouse warming (see Fig. 1d), including a larger warming rate along the equator than in the south-central part of

79 the basin (e.g. Collins et al. 2010; Cai et al. 2015) and a robust precipitation increase in the equatorial Pacific (e.g.

80 Watanabe et al. 2014; Li et al. 2016). This warming pattern also drives a drying of the southeast SPCZ margin in CMIP

81 models, which has been attributed to increased anomalous transport of dry subtropical air into the SPCZ region in

82 response to increased SST meridional gradients east of the southeast SPCZ margin (Widlansky et al. 2013). Within the

83 core of the SPCZ region, west of the dateline, two mechanisms compete in driving the rainfall changes (Widlansky et al.

84 2013): the thermodynamical "wet gets wetter" mechanism in which increased atmospheric water vapour content under

85 global warming tends to increase rainfall in the SPCZ convective region, and the dynamical "warmest gets wetter"

86 mechanism in which the comparatively weaker warming in the SPCZ region compared to that in the equatorial region

87 results in anomalous moisture divergence and hence tends to decrease rainfall. This results in a general tendency for the

88 SPCZ core to dry for moderate tropical warming $\left(\sim 1-2^{\circ} \mathrm{C}\right)$, when increased transport of moist air toward the equatorial

89 warming dominates the local increase of atmospheric moisture, and to moisten for stronger tropical warming $\left(\sim 3^{\circ} \mathrm{C}\right)$,

90 when local increase of atmospheric moisture dominates the dynamical changes (Widlansky et al. 2013). Finally, despite

91 the absence of consensus on how ENSO-driven SST variability may change in the future (Collins et al. 2010; Power et

92 al. 2013; Cai et al. 2015), CMIP model projections over the $21^{\text {st }}$ century do indicate a consistent intensification of

93 ENSO-related precipitation in the central/eastern equatorial Pacific because rainfall responds nonlinearly to absolute

94 SST. These climate model projections also display an increased occurrence of extreme El Niño and zonal SPCZ events

95 projected over the $21^{\text {st }}$ century because of a meridional SST gradient reduction in the South Pacific (Cai et al. 2012,

96 2014) allowing the SPCZ to shift equatorward more easily.

97 While the representation of tropical Pacific climate has slightly improved in CMIP5 models relative to CMIP3

98 models (Bellenger et al. 2014; Grose et al. 2014), these models still exhibit long-standing biases. They generally

99 produce an excessive equatorial cold tongue (Fig. 1c) that extends too far westward (Li and Xie 2014; Li et al. 2015;

100 Mechoso et al. 1995; Zheng et al. 2012; Fig. 1c) and a "double Intertropical Convergence Zone" bias (Brown et al.

101 2011; Grose et al. 2014; Irving et al. 2011; Niznik et al. 2015; Perkins 2011), i.e. a tendency for the SPCZ to be too

102 zonal and to extend too far eastward (Fig. 1a,b). The drying of the southeast SPCZ margin projected by CMIP models

103 (Fig. 1d) thus occurs in a region where these models do not correctly simulate the SPCZ (Fig. 1a,b). The precipitation

104 increase in the equatorial western Pacific (Fig. 1d) also occurs in a region where most CMIP models exhibit a cold bias

105 (Brown et al. 2013; Grose et al. 2014; Fig. 1c). Since many aspects of regional climate change depend upon the present-

106 day climatology (Held and Soden 2006; Matsueda and Palmer 2011; Huang et al. 2013; Xie et al. 2015), these model

107 biases may impair the reliability of projected future precipitation changes in the SPCZ region. Indeed, Li et al. (2016)

108 showed that the lower this cold bias, the larger the projected drying in the western Pacific (see their Fig 12). This clearly

109 indicates an influence of present-day SST biases on projected precipitation in CMIP5 models.

A possible strategy to reduce the impact of CMIP biases on climate change projections is to force an atmosphere-only model with bias-corrected SSTs (e.g. Knutson et al. 2008; Nguyen et al. 2012), i.e. to add the global 112 warming CMIP5 SST pattern to the present-day observed mean state. Several authors have used this strategy to assess the sensitivity of the SPCZ response to CMIP mean state biases (Brown et al. 2015; Evans et al. 2016; Widlansky et al. 
2013). Using a global atmospheric model, Widlansky et al. (2013) demonstrated that tropical mean SST biases in CMIP

115 models strongly contribute to the uncertainty of twenty-first-century rainfall projections in the South Pacific, with a 116 possible future drying of the western SPCZ portion when those biases are corrected. Using a bias-corrected SST 117 strategy in a number of regional climate models, Evans et al. (2016) showed that regional climate projections in the 118 southwest Pacific were much more sensitive to the choice of the regional climate model than to the CMIP model used to 119 specify the regional model boundary conditions. Overall, the ensemble of simulations performed in Evans et al. (2016)

120 display little consensus for projected SPCZ changes, although a majority of ensemble members project a drying of the 121 SPCZ, in line with Widlansky et al. (2013).

The above present-day bias-correction strategy does not, however account for possible biases in the warming 124 influence the projected SST pattern. A way to alleviate this issue is to use a simple statistical method based on the 125 relationship between CMIP5 present-day biases and projected changes, referred to as "observational constraint" or 126 "emergent constraint" (e.g. Bracegirdle and Stephenson 2012). Application of this approach reduced the impact of the 127 present-day model biases on the projected climate response in the Arctic (e.g. Bracegirdle and Stephenson, 2013) and 128 the Indian Ocean (Li et al. 2016; Parvathi et al. 2017). In the tropical Pacific, Li et al. (2016) applied this "observational 129 constraint" approach to correct CMIP5 projections in the tropical Pacific based on present-day rainfall bias in the 130 equatorial western Pacific. This strategy yielded a stronger warming in the eastern than in the western equatorial Pacific, and a strong reduction of the inter-model spread in the model precipitation projections. This method is further described

132 in section 2.2 and will be used in the present paper to correct CMIP5 SST projections and investigate the impact of this 133 correction on projected SPCZ changes.

Using a similar modelling framework as in Brown et al. (2015) and Evans et al. (2016), we investigate here the robustness of the SPCZ response to climate change to (i) present-day CMIP5 SST biases, (ii) projected CMIP5 SST $\left(\triangle \mathrm{SST}_{\mathrm{GW}}\right.$ ) biases and (iii) model physics. We specifically address the following questions: what are the expected robust changes in the austral summer SPCZ climatology in response to anthropogenic forcing? How will these changes alter the interannual SPCZ variability? The paper is organized as follows. Section 2 describes the experimental design. Section 3 provides a thorough evaluation of the SPCZ mean state and variability simulated by our present-day simulation, and an assessment of the impact of correcting for the present-day CMIP5 SST biases on the simulated SPCZ characteristics. Section 4 discusses the future changes in the SPCZ climatology and variability derived from our experimental strategy. We also discuss the sensitivity of our projections to the CMIP5 present-day SST biases and to the

143 CMIP5 projected SST pattern based on emergent constraints. Section 5 investigates the sensitivity of our results to the model physics. Finally, Section 6 provides a summary and a discussion of our results against previous studies.

\section{Experimental design and methods}

\subsection{WRF Regional model configuration}

In this study, the two different model configurations used and detailed in Table 1 are based on the Weather equations with the Advanced Research WRF dynamical solver (Skamarock and Klemp 2008). The simulated domain encompasses the tropical Pacific region $\left[101^{\circ} \mathrm{E}-59^{\circ} \mathrm{W} ; 26^{\circ} \mathrm{N}-42^{\circ} \mathrm{S}\right]$ using a $105 \mathrm{~km}$ horizontal grid spacing and 32 
pressure levels. In the following analyses, only a subset of this domain centred on the SPCZ region will be shown (Fig. 1a).

This first configuration is based on Lefèvre et al. (2016) study. It includes the Lin et al. (1983) microphysics scheme, the Community Atmosphere Model (Collins et al. 2004) for shortwave and longwave radiation, the UW planetary boundary layer (Bretherton and Park, 2009) with the Monin-Obukhov surface layer parameterization, and the Noah land surface model (Chen and Dudhia 2001). The parameterization of subgrid-scale convection is taken from the Zhang-McFarlane scheme (Zhang and McFarlane 1995). This configuration will be referred to as the "ZM" configuration in the following.

The second configuration is partly based on Jourdain et al. (2011) and Jullien et al. (2014). The set of physical parameterizations used is completely different from the ZM configuration with Betts-Miller-Janjić parameterization for convection (Janjić, 1994), the WRF single-moment three-class microphysics scheme (Hong et al. 2004), the Rapid Radiation Transfer Model for the longwave and shortwave radiation (Iacono et al. 2008) and the Yonsei University planetary boundary layer (Noh et al. 2003). This configuration will be referred to as the "BMJ" configuration in the following.

For conciseness, we will only discuss our results using ZM configuration in Section 3 and 4 but will discuss the consistency of the most salient results from these sections by comparing to the results obtained with BMJ configuration in Section 5.

\subsection{Present-day and climate change experiments}

The surface and lateral atmospheric boundary conditions were generated from the multi-model mean (MMM) of an ensemble of 31 CMIP5 climate models (Taylor et al. 2012). For each model, we consider the historical simulation and the projection over the $21^{\text {st }}$ century under the Representative Concentration Pathway 8.5 (RCP8.5) of aerosols and greenhouse gases (GHG) scenario, for which the radiative forcing reaches $8.5 \mathrm{~W} \cdot \mathrm{m}^{-2}$ by 2100 (van Vuuren et al. 2011). When several members were available for a given CMIP5 model, only the first available ensemble member was considered (referred to r1ilp1 in the CMIP5 naming convention, or r2i1p1 if not available) to avoid giving more weight to some models than others in the MMM. This equally weighted MMM is most often used as a "best" estimate for variable averages (Knutti et al., 2010), although this approach does not come without limitations because different models may only differ in their resolution or share the same atmospheric or oceanic components or similar physical parameterisations, and hence do not necessarily represent independent projection estimates (Herger et al., 2018; Knutti et al., 2017). The CMIP5 fields used to build the boundary conditions and the initial state are listed in Table 2 . Table 3 provides a summary of the performed simulations, which are further detailed in the following.

A pair of present-day (PD) simulations is performed for each of the two model configurations (ZM and BMJ), from January 1980 to May 2016. For each of the ZM and BMJ configurations (indicated by subscripts in the acronyms when needed), a 36-yr present-day simulation (labelled PD_OBS hereafter) has been designed as a dynamical downscaling of the NCEP2 reanalysis (NCEP2; Kanamitsu et al. 2002). Surface and lateral boundary conditions are taken from the 6-hourly outputs of this reanalysis. A second 36-yr present-day simulation uses the same NCEP2 boundary conditions to which the present-day monthly climatological CMIP5 MMM SST bias is added to the observed SST climatology (labelled PD_CMIP hereafter). SST biases are only applied in the SPCZ region, within $\left[130^{\circ} \mathrm{E}-290^{\circ} \mathrm{E}\right.$; $7^{\circ} \mathrm{N}-30^{\circ} \mathrm{S}$ ], with a smooth transition to present-day SST near the boundaries of this region. The lateral and sea surface 
PD_OBS simulation allows assessing the impact of the historical CMIP5 SST biases on the present-day SPCZ representation. In all these present-day simulations, the $\mathrm{CO}_{2}$ forcing is kept constant at a level representative of the recent period $(379 \mathrm{ppm})$.

To assess the southwest Pacific response to climate change (CC), we further conduct a set of three future experiments for each model configuration. For the first two experiments (labelled CC_OBS and CC_CMIP), we apply the climatology of surface and lateral boundary future changes on top of the conditions of PD_OBS and PD_CMIP. These future changes are calculated as the difference between the 2080-2100 and 1989-2009 periods of MMM monthly climatologies (Fig. 1d), following the same methodology as in Knutson et al. (2008) and Walsh (2015). In these simulations, we apply a constant $\mathrm{CO}_{2}$ forcing representative of the RCP8.5 projections at the end of the $21^{\text {st }}$ century (845ppm). The CMIP5 fields used to build the boundary conditions and the initial states are listed in Table 2 . This experimental strategy intentionally assumes no change in interannual variability between the present and future climate for two main reasons. First, the reported lack of consensus on changes in amplitude of ENSO-related SST signals in future CMIP model projections (some global climate models showing an increase in the amplitude of ENSO SST variability in the future, others showing a decrease or, no statistically significant changes; see Bellenger et al. 2014) are a motivation to test the null hypothesis, i.e. that the ENSO SST variability will not significantly change. Second, Cai et al. (2012) found a consistent increase in the frequency of zonal SPCZ events despite this lack of consensus and attributed this increase to the changes in the mean meridional SST gradient in the South Pacific. The present experimental framework that only assumes a mean state change permits examination of whether the mechanism suggested by Cai et al. (2012) operates in a more realistic framework (i.e. without CMIP5 mean present-day biases).

The third experiment (CC_COR) is similar to CC_OBS experiment, except that it uses the CMIP5 SST anomalous pattern (Fig. 1e) statistically corrected following the method of Li et al. (2016, In order to produce a corrected SST projection, we first assess the statistical relationship between the historical rainfall bias and the projected SST warming in the equatorial western Pacific $\left(140^{\circ} \mathrm{E}-170^{\circ} \mathrm{W} ; 2^{\circ} \mathrm{S}-2^{\circ} \mathrm{N}\right)$ among CMIP5 models. We find a significant correlation of $-0.56(\mathrm{p}$-value $=0.001)$ between these parameters $\Delta \mathrm{SST}_{\mathrm{GW}}$ across $31 \mathrm{CMIP5}$ models (Fig. 2), which agrees well with the results of $\mathrm{Li}$ et al. (2016) who found a -0.52 correlation across 24 CMIP5 models (their Fig. 6a). This analysis demonstrates that the drier the present-day west Pacific (and the stronger the cold tongue bias, not shown), the stronger the projected SST warming in the equatorial western Pacific. As in Li et al. (2016), we use this linear relation between the mean western equatorial Pacific present-day precipitation and future warming to correct the tropical Pacific warming pattern. The corrected CMIP5 MMM projection exhibits a weaker western Pacific warming (Fig. 1e). This will significantly modify SST gradients in this region, relative to the uncorrected warming pattern.

In the rest of the manuscript we will refer to the difference between historical CMIP5 climatological SST, and observed SST as the "historical CMIP5 SST bias" and to the difference between corrected and uncorrected SST warming pattern as the "projected CMIP5 SST bias" strictly speaking, this last quantity is not bias but an estimated bias.

\subsection{Analysis methods}

The SPCZ position at each longitude is taken as the location of the maximum precipitation between the equator and $30^{\circ} \mathrm{S}$, where the rainfall amount is larger than $6 \mathrm{~mm}^{-d a y^{-1}}$. The mean SPCZ slope is calculated as a linear fit to this SPCZ position between $160^{\circ} \mathrm{E}$ and $140^{\circ} \mathrm{W}$. As in Vincent et al. (2011), we define LatW as the SPCZ latitude average 
between $160^{\circ} \mathrm{E}$ and $180^{\circ} \mathrm{E}$, and latE as the SPCZ latitude averaged between $170^{\circ} \mathrm{W}$ and $150^{\circ} \mathrm{W}$. El Niño (La Niña) events are defined as austral summer seasons (December-January-February; DJF) when the DJF Niño3.4 SST anomaly

233 is greater (lower) than $0.5^{\circ} \mathrm{C}$, following NOAA's index:

234 http://www.cpc.noaa.gov/products/analysis monitoring/ensostuff/ensoyears.shtml. Following Santoso et al. (2017), we 235 classify El Niño events into two classes: extreme El Niño events that encompass the three largest events (1982/1983, 1997/1998, 2015/2016) and moderate El Niño events that gather all the other events.

To investigate the relative importance of moisture changes (referred to as "thermodynamical") and large-scale atmospheric circulation changes (referred to as "dynamical") in shaping the pattern of moisture divergence changes between future and present, we use the same method as in Widlansky et al. (2013) with a simple decomposition of surface moisture divergence changes (the anomaly being the difference between $\mathrm{CC}_{-} \mathrm{OBS}_{\mathrm{ZM}}$ and $\mathrm{PD}_{-} \mathrm{OBS} \mathrm{ZM}_{\mathrm{ZM}}$ ) into

241 surface divergence of:

- projected moisture changes advected by the mean circulation:

$$
\delta T H=\nabla \cdot\left(\bar{u} q^{\prime}\right)
$$

- mean moisture advected by the projected circulation changes:

$$
\delta D Y N=\nabla \cdot\left(u^{\prime} \bar{q}\right)
$$

where $u$ is the horizontal surface wind vector, $q$ is the specific surface humidity, the overbar denotes the values from the present day simulation and primes denote differences between future and present day simulations. The cross terms are not discussed here as $\delta T H$ and $\delta D Y N$ dominate the balance in the region of interest (not shown).

\section{Results: Present-day simulations}

\subsection{Climatological features}

In observations, the SPCZ persists throughout the year but reaches its maximum extension during austral summer (DJF). At this time of the year, Figure 3a shows that the SPCZ extends from $2^{\circ} \mathrm{S}$ on its western edge to $22^{\circ} \mathrm{S}$ on its eastern edge and exhibits a moderate tilt in its western portion $\left(150^{\circ} \mathrm{E}-160^{\circ} \mathrm{W}\right)$ and a larger southeastward tilt in its eastern portion $\left(160^{\circ} \mathrm{W}-140^{\circ} \mathrm{W}\right)$. The surface winds converge toward the SPCZ.

The PD_OBS $\mathrm{ZM}_{\mathrm{ZM}}$ experiment simulates the observed climatological DJF precipitation pattern reasonably well (Fig. 3b), including the southeastward SPCZ tilt. The surface wind intensity and convergence are correctly reproduced, resulting in a realistic moisture convergence (not shown). This simulation however exhibits some biases, including a $\sim 12 \%$ underestimation of Inter Tropical Convergence Zone (ITCZ) rainfall and a $\sim 30 \%$ underestimation of the western

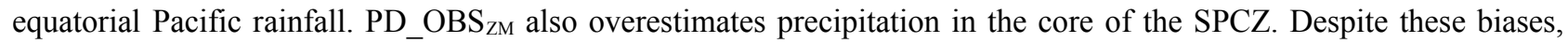
this simulation reproduces the location of the observed SPCZ very accurately (yellow and red curves on Figure 3a), a major asset for the objectives of the present study. In addition, this simulation better captures the position of SPCZ than the other studies using regional models (Evans et al. 2016).

This rainfall pattern in PD_OBS $\mathrm{ZM}$ is further compared to the one from NCEP2 reanalysis (Fig. 3c), which is used as boundary conditions of PD_OBS precipitation pattern reasonably well. In contrast to PD_OBS $\mathrm{ZM}_{\mathrm{ZM}}$, it tends to overestimate ITCZ $(\sim 15 \%)$ and equatorial western Pacific $(\sim 5 \%)$ precipitation. The NCEP2 dataset also exhibits a diagonally oriented SPCZ, although this reanalysis appears to overestimate the SPCZ tilt in its western portion relative to PD_OBS ${ }_{\mathrm{ZM}}$ and observations and 
underestimate it in its eastern portion. Like PD_OBS $\mathrm{ZM}_{\mathrm{Z}}$, NCEP2 reanalysis overestimates precipitation in the core of the SPCZ.

A more quantitative assessment of the SPCZ climatological characteristics simulated by PD_OBS $\mathrm{ZM}(\mathrm{red}$

270 circle), NCEP2 (green circle) and CMIP5 models (boxplot) is provided in Figure 4. Figure 4a clearly illustrates that all

271 CMIP5 models considerably underestimate the slope of the SPCZ as already reported in past literature (e.g. Brown et al.

272 2012), with the historical CMIP5 MMM exhibiting a slope $\left(0.06^{\circ} \mathrm{S} /{ }^{\circ} \mathrm{E}\right)$ that is $25 \%$ of the observed slope $\left(0.26^{\circ} \mathrm{S} /{ }^{\circ} \mathrm{E}\right)$.

273 This slope varies considerably between individual CMIP5 simulations, ranging from a completely zonal SPCZ to a

274 more realistic but still underestimated diagonally-oriented SPCZ slope (of up to $0.14^{\circ} \mathrm{S} /{ }^{\circ} \mathrm{E}$ ). As expected, when an

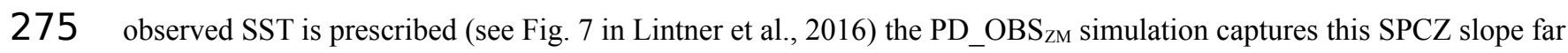

276 more accurately $\left(0.22^{\circ} \mathrm{S} /{ }^{\circ} \mathrm{E}\right)$. The strong underestimation of the SPCZ slope in historical CMIP simulations largely

277 results from a large northward bias in the location of its eastern portion (Fig. $4 \mathrm{~b} ; 9^{\circ} \mathrm{S}$ for the CMIP MMM, $13.5^{\circ} \mathrm{S}$ for

278 observations). This location is very well captured in $\mathrm{PD}_{-} \mathrm{OBS}_{\mathrm{ZM}}\left(14^{\circ} \mathrm{S}\right)$. The location of the western SPCZ portion (Fig.

$2794 \mathrm{c}$ ) around $8^{\circ} \mathrm{S}$ is reasonably well captured by PD_OBS $\mathrm{ZM}_{\mathrm{ZM}}$, NCEP2 and CMIP5 simulations. PD_OBS

280 captures the South Pacific $\left(0-30^{\circ} \mathrm{S} ; 150^{\circ} \mathrm{E}-240^{\circ} \mathrm{E}\right)$ rainfall pattern (Fig. $\left.4 \mathrm{~d}\right)$, with a pattern correlation to the observed

281 rainfall of 0.96 , compared to a correlation ranging from 0.5 to 0.9 for CMIP5 and 0.87 for NCEP2. Overall, PD_OBS $\mathrm{ZM}$

282 behaves as accurately or slightly better than NCEP2, as far as the SPCZ climatological features are concerned.

283

284

285

286

287

288

289

290

291

292

293

294

295

296

297

298

299

300

301

302

303

304

305

\subsection{Interannual variability}

Figure 5 displays composites of anomalous rainfall and surface winds during the different ENSO phases, which are very similar in both observations (Fig. 5ac) and PD_OBS

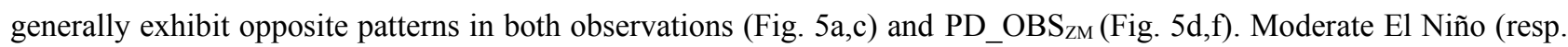
La Niña) events are characterized by modest positive (negative) rainfall anomalies in the vicinity of the dateline, while weak negative (positive) rainfall anomalies prevail in the western equatorial Pacific and south of the climatological SPCZ position in the southwest Pacific. During these moderate El Niño events (resp. La Niña), the SPCZ experiences a $3^{\circ}$ northward (southward) shift between $150^{\circ} \mathrm{E}$ and $150^{\circ} \mathrm{W}$. This picture is very different during extreme El Niño events in both observations (Fig. 5b) and $\mathrm{PD}_{-} \mathrm{OBS}_{\mathrm{ZM}}$ (Fig. 5e): the equatorial rainfall increase is four times larger than during moderate El Niño events and its pattern is considerably extended and shifted eastward, with a maximum near $160^{\circ} \mathrm{W}$. The South Pacific rainfall decrease is also about twice as large as during moderate events and extends further east to $140^{\circ} \mathrm{W}$. Finally, the area covered by the ITCZ in the western equatorial Pacific also exhibits a large drying that is not present during moderate El Niño events. These stronger and spatially-extended rainfall anomalies associated with extreme observed and modelled El Niño events translate into larger SPCZ displacements: the SPCZ eastern portion shifts northward by up to ten degrees, while its western portion remains close to its climatological position, resulting in a more zonally oriented SPCZ from $150^{\circ} \mathrm{E}$ to $150^{\circ} \mathrm{W}$.

From year to year, the eastern portion of the observed SPCZ experiences meridional displacements, with the largest northward excursions occurring in austral summer of years $1982\left(\sim+10^{\circ}\right), 1992\left(\sim+7^{\circ}\right), 1997\left(\sim+10^{\circ}\right)$ and 2015 $\left(\sim+8^{\circ}\right)$ (Fig. 6). As discussed in Vincent et al. (2011), these years are indeed characterized by an extreme northward swing of the SPCZ, which ends up with a more zonally oriented structure. PD_OBS $\mathrm{ZM}$ and NCEP2 reasonably reproduce these SPCZ excursions ( 0.71 Pearson correlation coefficient between observations and both datasets; $\mathrm{p}$-value $<1.10^{-6}$ ), despite a $20 \%$ overestimation of the variability in NCEP2 (NCEP2 STD $=4.99^{\circ}$ vs $\left.\mathrm{CMAP} \mathrm{STD}=4.1^{\circ}\right)$. In particular, 
PD_OBS $\mathrm{ZM}_{\mathrm{M}}$ correctly simulates the SPCZ extreme northward excursions during the 1982, 1992, 1997 and 2015 El Niño events, with a tendency for both PD_OBS $\mathrm{ZM}$ and NCEP2 to overestimate the northward excursion of the SPCZ during

308 these events (Fig. 6). The variability of the western portion is also well captured by both NCEP2 and PD_OBS 309 shown), with a $\sim 0.7$ correlation (p-value $<1.10^{-7}$ ) to CMAP. Overall, this section demonstrates the capacity of our simulation to reproduce reasonably well the present-day SPCZ mean state as well as its interannual variability.

\section{Results: Response to climate change}

\subsection{Climatology}

In this section, we investigate the climatological SPCZ changes in response to anthropogenic forcing in our three sets of experiments $-\mathrm{CMIP}_{\mathrm{ZM}}$, i.e. the difference between $\mathrm{CC}_{-} \mathrm{CMIP}_{\mathrm{ZM}}$ and $\mathrm{PD}_{-} \mathrm{CMIP}_{\mathrm{ZM}}$; $\mathrm{OBS}_{\mathrm{ZM}}$, i.e. the difference between CC_OBS $\mathrm{ZM}$ and PD_OBS and compare these with the CMIP5 MMM. We start with a description of the projected SPCZ changes in CMIP5

318 MMM, and then compare them with that in $\mathrm{CMIP}_{\mathrm{ZM}}$ experiments to assess the impact of our model setup. We will then compare the results from $\mathrm{CMIP}_{\mathrm{ZM}}$ and $\mathrm{OBS}_{\mathrm{ZM}}$ experiments to evaluate the impact of the historical CMIP5 SST bias on the projected SPCZ changes. Finally, we will compare $\mathrm{OBS}_{\mathrm{ZM}}$ and $\mathrm{COR}_{\mathrm{ZM}}$ experiments to evaluate the effect of the projected CMIP5 warming pattern bias on the projected SPCZ changes.

Projected CMIP5 MMM precipitation changes are characterized by a consistent and significant rainfall

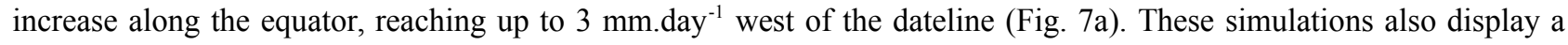

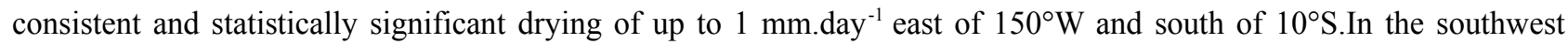
Pacific $\left(10^{\circ} \mathrm{S}-30^{\circ} \mathrm{S} ; 160^{\circ} \mathrm{E}-160^{\circ} \mathrm{W}\right)$ rainfall changes are not statistically significant among models in the sense that less than $75 \%$ of the CMIP models simulate a rainfall increase. Overall, these modest rainfall changes only result in very modest future changes in the climatological SPCZ location in CMIP5 simulations (solid and doted black lines in Figure 7a) but are related to an intensification of the trade winds in the southeastern part of the domain, converging towards the equatorial region (Fig. 7a).

We first explore how projections performed with our model forced with present-day and future CMIP5

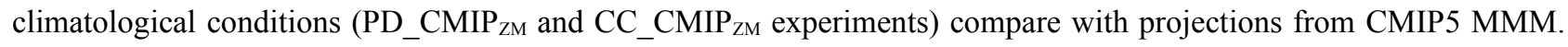
Our set of $C M I P 5_{Z M}$ simulations displays a similar and significant precipitation increase in the equatorial region compared to CMIP5 MMM (Fig 7b), with a $\sim 2.5$ mm.day $^{-1}$ increase (48\%) in CMIP ZM $_{\text {zM }}$ experiments compared to $\sim 2.2$ mm.day ${ }^{-1}$ increase (37\%) in CMIP5 MMM when averaged over the western/central equatorial Pacific $\left[5^{\circ} \mathrm{S}-5^{\circ} \mathrm{N} ; 150^{\circ} \mathrm{E}-\right.$ $160^{\circ} \mathrm{W}$; red box on Fig. 7d]. As CMIP5 MMM, our set of CMIP $5_{\mathrm{ZM}}$ simulations also yield a significant drying of the southeast SPCZ margin, extending westward up to $175^{\circ} \mathrm{E}$. This drying in CC_CMIP5 $5_{\mathrm{ZM}}$ is however stronger than in CMIP5 MMM, with a $\sim 1.0 \mathrm{~mm}^{\text {.day }}{ }^{-1}$ rainfall decrease in $\mathrm{CMIP}_{\mathrm{ZM}}$ experiments $(-20 \%)$ compared to $\sim 0.4 \mathrm{~mm}^{- \text {day }^{-1}}$ in CMIP5 MMM (-7\%) when averaged over the south-central Pacific $\left[5^{\circ} \mathrm{S}-15^{\circ} \mathrm{S} ; 180^{\circ}-150^{\circ} \mathrm{W}\right.$; green box on Fig. $\left.7 \mathrm{~d}\right]$. As in CMIP5 MMM, these changes in CMIP5 $5_{\mathrm{ZM}}$ do not affect the climatological SPCZ position, which remains similar from $150^{\circ} \mathrm{E}$ to $160^{\circ} \mathrm{W}$ (solid and doted black lines on Figure $7 \mathrm{~b}$ ). The rainfall decrease east of $170^{\circ} \mathrm{W}$ however leads to a shrinkage of the SPCZ (see eastward extend of the plain and dashed lines on Fig. 7b). CC_OBS $S_{\mathrm{ZM}}$ experiments) impacts the projected rainfall pattern (Fig. 7b,c). CC_OBS $\mathrm{ZM}$ also experiences a significant 
rainfall increase in the equatorial region between $7^{\circ} \mathrm{S}-10^{\circ} \mathrm{N}$ (Fig. 7c) reaching a maximum in the western/central 345 Pacific, near $5^{\circ} \mathrm{N}$. This rainfall increase is however stronger than $\mathrm{CC}_{-} \mathrm{CMIP}_{\mathrm{ZM}}(66 \%$ increase from PD_OBS $\mathrm{ZM}$ to 346 CC_OBS $\mathrm{ZM}_{\mathrm{ZM}}$ compared to $48 \%$ increase from PD_CMIP $\mathrm{ZM}_{\mathrm{ZM}}$ to CC_CMIP $\mathrm{ZM}$ when averaged over the equatorial Pacific 347 box). CC_OBS $\mathrm{ZM}_{\mathrm{ZM}}$ also exhibits a significant drying of the southeast SPCZ margin (15\% rainfall decrease when averaged 348 over box the south-central Pacific green box on Fig. 7d), similar to that in CC_CMIP ${ }_{\mathrm{ZM}}(20 \%)$. CC_OBS 349 experiences a larger and more extended wettening south of the climatological SPCZ position compared to CC_CMIP $\mathrm{ZMM}_{\mathrm{ZM}}$. As opposed to $\mathrm{CMIP}_{\mathrm{ZM}}$ experiments, these large-scale and intense changes affect the climatological SPCZ position in its eastern portion (solid and doted black lines on Figure 7c), with a $4^{\circ}$ southward shift of the maximum precipitation.

We examine the effect of correcting the projected CMIP5 SST bias by comparing $\mathrm{OBS}_{\mathrm{ZM}}$ to $\mathrm{COR}_{\mathrm{ZM}}$ experiments. CC_COR $\mathrm{ZM}$ (Fig. 7d) yields a weaker increase of precipitation in the western/central equatorial region (30\% increase when averaged over the equaotrial Pacific box) compared to CC_OBS $\mathrm{ZM}_{\mathrm{ZM}}$ (66\% increase). The area of significant increase located north of the equator is confined in the western Pacific in $\mathrm{CC}_{-} \mathrm{COR}_{\mathrm{ZM}}$ while it extends throughout the Pacific in $\mathrm{CC}_{-} \mathrm{OBS}_{\mathrm{ZM}}$. CC_COR $\mathrm{ZM}$ also yields a larger drying of the southeast SPCZ margin (-35\% when averaged over the south-central Pacific green box on Fig. 7d), compared to CC_OBS $\mathrm{ZM}$ (-15\%) and CC_CMIP $\mathrm{ZM}_{\mathrm{ZM}}(-$

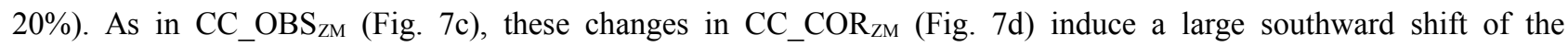
climatological SPCZ position east of the dateline $\left(\sim 4^{\circ}\right)$. In addition, this drying in CC_COR $\mathrm{ZM}$ also extends farther into the western Pacific (see for instance the area in the blue box on Fig. 7d) than in CC_OBS ${ }_{\mathrm{ZM}}, \mathrm{CC}_{-}$CMIP $\mathrm{ZM}_{\mathrm{ZM}}$ and CMIP5 MMM (Fig. 7). In the blue box in Figure 7d, the drying represents a $25 \%$ rainfall decrease in CC_COR ${ }_{\text {ZM }}$ compared to present-day climatology, while it represents only $-1 \%$ in CC_OBS ${ }_{\mathrm{zM}},-7 \%$ in CC_CMIP $\mathrm{ZM}_{\mathrm{zM}}$, and $+3 \%$ in CMIP5 MMM. Finally, the trade winds in the south-central part of the domain $\left[180^{\circ} \mathrm{E}-150^{\circ} \mathrm{W} ; 15^{\circ} \mathrm{S}-5^{\circ} \mathrm{S}\right]$ increase by $40 \%$ compared to present-day climatology in $\mathrm{CC}_{-} \mathrm{COR}_{\mathrm{ZM}}$, especially in the southwestern Pacific where maximum precipitation changes are found.

We further use simple surface moisture convergence diagnostics similar to those proposed in Widlansky et al. (2013) and detailed in Section 2 to provide insights on the mechanisms driving the simulated rainfall response to climate change in CMIP5 models and in our experiments (Fig. 8). The anomalous changes in surface moisture divergence (Figure 8a,b,c,d) qualitatively match those of the precipitation changes (Fig. 7a,b,c,d) for both CMIP5 models and our experiments, indicating that this is an appropriate way to diagnose precipitation changes. Moisture divergence changes are almost entirely driven by wind divergence changes in our experiments and in CMIP5 models (Fig. 8e,f,g,h), with moisture changes playing a smaller role (Fig. 8i,j,k,l). The anomalous moisture convergence in the equatorial region is also largely driven by dynamical changes, with thermodynamics only damping the dynamical changes (Fig. 8e,f,g,h vs i,j,k,l). Thermodynamical effects are slightly stronger in CMIP5 $5_{\mathrm{ZM}}$ (Fig. 8j) than in $\mathrm{OBS}_{\mathrm{ZM}}$ (Fig. 8k), and hence damp the dynamical effect more, leading to larger precipitation changes in $\mathrm{OBS}_{\mathrm{zM}}$ in the equatorial region. In the south-central Pacific (the green box region), the increased anomalous moisture divergence that dries the SPCZ eastern edge is also largely driven by circulation changes (Fig. 8e,f,g,h).

In the southwest Pacific (blue box region), $\mathrm{COR}_{\mathrm{ZM}}$ experiments yield a stronger drying of the SPCZ western margin, which can be related to stronger dynamical processes (Fig. 8h) compared to $\mathrm{OBS}_{\mathrm{ZM}}$ (Fig. 8g) and $\mathrm{CMIP}_{\mathrm{ZM}}$ (Fig. 8f). In the two latter simulations, dynamical effects are more balanced by thermodynamical effects. The wind changes responsible for these moisture convergence modifications between $\mathrm{OBS}_{\mathrm{ZM}}$ and $\mathrm{COR}_{\mathrm{ZM}}$ can be related to the corrected projected SST patterns (Fig. 1d,e). Changes in SST meridional gradients between the equatorial western Pacific $\left(160^{\circ} \mathrm{E}-\right.$ $\left.180 ; 5^{\circ} \mathrm{S}-5^{\circ} \mathrm{N}\right)$ and the southwestern Pacific $\left(160^{\circ} \mathrm{E}-180 ; 5^{\circ} \mathrm{S}-15^{\circ} \mathrm{S}\right)$ are stronger in $\mathrm{COR}_{\mathrm{ZM}}\left(0.33^{\circ} \mathrm{C}\right.$ in $\mathrm{COR}_{\mathrm{ZM}}$ vs. $0.028^{\circ}$ 
in $\left.\mathrm{OBS}_{\mathrm{ZM}}\right)$. SST zonal gradients between the southwestern Pacific $\left(150^{\circ} \mathrm{E}-180 ; 5^{\circ} \mathrm{S}-15^{\circ} \mathrm{S}\right)$ and the south central Pacific $\left(180-210^{\circ} \mathrm{E} ; 5^{\circ} \mathrm{S}-15^{\circ} \mathrm{S}\right)$ are also slightly greater in $\mathrm{COR}_{\mathrm{ZM}}\left(0.58^{\circ} \mathrm{C}\right.$ in $\mathrm{COR}_{\mathrm{ZM}}$ vs. $0.54^{\circ} \mathrm{C}$ in $\left.\mathrm{OBS}_{\mathrm{ZM}}\right)$. Overall, these different SST gradients induce southeasterly wind changes (blowing from the southeast Pacific dry zone towards the central and western equatorial Pacific) that are stronger and extend further into the western Pacific in CC_COR ${ }_{Z M}$ experiment (Fig. 7c vs 7d).

To summarize, the above results demonstrate that (1) the historical CMIP5 SST biases damp the intensity of the equatorial rainfall response compared to $\mathrm{OBS}_{\mathrm{zM}}$, largely through thermodynamical processes and (2) the projected SST correction yields a larger drying of the SPCZ western portion, due to southeasterlies that penetrate further west and north in relation with SST gradient changes.

\subsection{Interannual variability}

A general assessment of the changes in rainfall interannual variability between present and future climate is provided in Figure 9. In $\mathrm{PD}_{-} \mathrm{OBS}_{\mathrm{ZM}}$, large interannual rainfall variations (4 to $8 \mathrm{~mm}$.day ${ }^{-1}$ ) are found in a large region extending from $150^{\circ} \mathrm{E}$ to $150^{\circ} \mathrm{W}$ and $8^{\circ} \mathrm{N}$ to $20^{\circ} \mathrm{S}$, with a maximum in the SPCZ core region and under the ITCZ (Fig. 9a). Rainfall interannual variability is considerably affected by anthropogenic forcing (Fig. 9b,c), with a near doubling of the amplitude of equatorial rainfall variability between $\mathrm{PD}_{-} \mathrm{OBS}_{\mathrm{ZM}}$ and $\mathrm{CC}_{-} \mathrm{OBS} \mathrm{ZM}_{\mathrm{ZM}}$. In $\mathrm{COR}_{\mathrm{ZM}}$ experiments, the anthropogenic forcing also affects the South Pacific rainfall variability, with a reduction of rainfall variability south of $5^{\circ} \mathrm{S}$. This rainfall change is likely related to the drying of SPCZ in its western part. Similar results are found in the $\mathrm{CMIP}_{\mathrm{ZM}}$ experiments (not shown). In a more idealized framework, Chung et al. (2014) also found that global warming enhances the nonlinear rainfall response to ENSO SST anomalies, with an increase of precipitation variability, especially along the equator. Our study confirms these results in a more realistic framework.

Enhanced precipitation in the equatorial region however does not appear to be robust for all ENSO phases in $\mathrm{COR}_{\mathrm{ZM}}$ experiments (Fig. 10abc). The large equatorial rainfall increase under climate change is indeed clear for El Niño events (Fig. 10ab) but considerably weaker for La Niña events, being largely confined to the far western Pacific (Fig. 10c). This is also the case in the $\mathrm{OBS}_{\mathrm{zM}}$ and $\mathrm{CMIP}_{\mathrm{zM}}$ experiments (not shown). To further illustrate that, Figure 10d,e provides scatterplots of the rainfall difference between future and present climate for each of 36 simulated austral summers in each of our experiments as a function of the ENSO state in the two regions drawn on the upper panels of Figure 10: the equatorial region (Fig. 10d) and the South Pacific region (Fig. 10e). The amplitude of the equatorial precipitation increase is considerably larger for an El Niño (up to $2.5 \mathrm{~mm} /$ day) than for a La Niña $(\sim 0 \mathrm{~mm} /$ day). This illustrates the non-linearity of the precipitation response to climate change during ENSO phases, as demonstrated by Chung et al. (2014) in a more idealized framework. The South Pacific drying in response to climate change has a weaker non-linear dependency to ENSO (-1 mm.day ${ }^{-1}$ for La Niña vs. $2.5 \mathrm{~mm}_{\text {.day }}{ }^{-1}$ for El Niño) than the equatorial region (Fig. 10e).

The changes in rainfall interannual variability near the equator are mostly driven by changes in the SPCZ response to ENSO (Fig. 11). Under present-day conditions, the zonally-oriented SPCZ during extreme El Niño events remains largely located in the Southern Hemisphere (red thick line; Fig. 11a), with the largest northward excursion of $12^{\circ}$ occurring in $\mathrm{PD}_{-} \mathrm{OBS}_{\mathrm{ZM}}$ during the 1997-1998 event. The SPCZ shifts right onto the equator between $165^{\circ} \mathrm{E}$ and $140^{\circ} \mathrm{W}$ in $\mathrm{CC}_{-} \mathrm{COR}_{\mathrm{ZM}}$ (red dashed line; Fig. 11a), and between $180^{\circ} \mathrm{E}$ and $140^{\circ} \mathrm{W}$ in $\mathrm{CC}_{-} \mathrm{OBS}_{\mathrm{ZM}}$ (not shown), resulting in a northward excursion exceeding $15^{\circ}$ during extreme El Niño events (1983, 1992, 1998, 2016) (red dashed lines, Fig. 
11a). During moderate El Niño events, the SPCZ in both $C_{-} C_{C O R}$ ZM (Fig. 11b) and CC_OBS experiences a shift of $\sim 3^{\circ}$ near the dateline but a far weaker southward excursion in its eastern portion. During la Niña events, the SPCZ position slightly moves southward by $2^{\circ}$ in both present and future climates (Fig. 11c).

The SST cold bias in CMIP5 models yields weaker ENSO-related SPCZ present-day movements in PD_CMIP5 $5_{\mathrm{ZM}}$ (black dashed line versus black thick line; Fig. 11d,e,f) than in PD_OBS ${ }_{\mathrm{ZM}}$ (black dashed line versus black thick line; Fig. 11a,b,c). Under climate change, this SPCZ variability increases in CC_CMIP5 ${ }_{\mathrm{ZM}}$ (STD LatE PD_CMIP5 $5_{\mathrm{ZM}}=3.04^{\circ}$; STD LatE CC_CMIP5 $5_{\mathrm{ZM}}=4.96^{\circ}$ ), yielding larger northward SPCZ shifts during the future conditions than in the current day, for both strong and moderate El Niños. There are thus larger northward displacements of the SPCZ during El Niños in the future than in the present day, especially in our bias-corrected experiments. But what about the frequency of those zonal events? Cai et al. (2012) demonstrated a near-doubling of SPCZ zonal events frequency in CMIP models under climate change, and linked this increase to a decreased SST meridional gradient south of the equator. To assess the robustness of this result in our experiments, we computed Empirical Orthogonal Functions (EOFs) of precipitation from our regional simulations and identified zonal SPCZ events from the value of the first two principal components as in Cai et al. (2012) (Figure 12). There are four SPCZ zonal events (red circle, Fig. 12 a,b) in both of our present-day simulations (PD_OBS ZM $_{\text {and PD_CMIP5 }}$ am $)$ corresponding to 1982/1983, 1991/1992, 1997/1998 and 2015/2016 El Nino years. Contrary to what was found by Cai et al. (2012), we find the same number of SPCZ zonal events in the CC_COR $\mathrm{ZM}_{\mathrm{ZM}}, \mathrm{CC}_{-} \mathrm{OBS} \mathrm{ZM}_{\mathrm{ZM}}$ and CC_CMIP5 $5_{\mathrm{ZM}}$ climate change experiments, i.e. the doubling of zonal SPCZ events under future climate conditions is not robust to a change in model physics (CC_CMIP5 $5_{\mathrm{zM}}$ ), and does not occur either when additionally correcting for the historical CMIP5 SST bias or the warming pattern bias.

To conclude, in line with Power et al. (2013), our global warming experiments increase the interannual rainfall variability near the equator and decreases it under the SPCZ, resulting in an enhanced SPCZ interannual variability, especially when the SST projections are corrected. The increased equatorial rainfall variability is mainly related to the non-linear precipitation response to ENSO. However, the doubling of SPCZ zonal events discussed by Cai et al. (2012) is not robust in our simulations.

\section{Sensitivity tests}

\subsection{Sensitivity of the response to the model physics configuration}

It is crucial to assess the robustness of our findings with regards to the regional model physics, since it has a strong impact on how the SPCZ responds to climate change (e.g. Evans et al. 2016). To that end, we ran experiments with a completely different set of physical parameterizations that also yields a realistic representation of the South Pacific region climate (see BMJ configuration described in section 2; Jourdain et al. 2011; Jullien et al. 2014).

The climatological rainfall pattern (blue circles on Fig. 4) and those induced by ENSO variations (not shown) are also reasonably well simulated by that model configuration. PD_OBS and latitude of the SPCZ eastern portion (Fig. 4b). However, it displays a $3^{\circ}$ southward bias of the SPCZ western portion (Fig. 4c), resulting in a 25\% underestimation of the SPCZ slope (Fig. 4a). In addition, this simulation exhibits a considerably reduced dry equatorial bias relative to PD_OBS 
4b,c). Despite the differences in their present-day SPCZ climatology, the ZM and BMJ configurations yield a qualitatively similar response to climate change, with a large rainfall increase in the equatorial Pacific in both CC_COR

463 and CC_OBS (Fig 13a,b vs Fig 7c,d). As in ZM, correcting the CMIP5 mean state cold bias also yields a larger precipitation increase in the tropical region (Fig. 13b,c) and correcting the projected SST change yields a larger drying of the SPCZ western portion (Fig. 13a,b). The main difference between BMJ and ZM configurations is a larger ITCZ drying ( $\sim 20 \%$ in BMJ vs $\sim 10 \%$ in $\mathrm{ZM}$ ) and overall more intense future changes in the BMJ configuration. These anomalous rainfall patterns result in both OBS and COR experiments in a southward shift $\left(\sim 3^{\circ}\right)$ of the climatological SPCZ position from present day to future (black thick line vs black dashed line; Fig 13a,b) similar to that in the ZM configuration. In addition, as in ZM, the variability of the SPCZ eastern portion and its northward shift also increase in the future for our BMJ experiments (not shown; STD LatE PD_OBS BMJ $_{1}=5.3^{\circ}$; STD LatE CC_OBS BMJ $=8^{\circ}$; and STD LatE CC_COR ${ }_{\text {BM }}=7.8^{\circ}$ to be compared to STD LatE PD_OBS ${ }_{\mathrm{ZM}}=4.24^{\circ}$; STD LatE CC_OBS LatE CC_COR $\left.{ }_{\mathrm{ZM}}=6.18^{\circ}\right)$. Finally, as in ZM, the number of SPCZ zonal events does not increase under climate change in any of our BMJ simulations (not shown).

Overall, the main conclusions derived from the ZM configuration remain valid under a very different set of model parameterisations.

\subsection{Comparison with CMIP5 models}

A summary of the mechanisms responsible for the response of precipitation to climate change in the equatorial and South Pacific regions in CMIP5 models and our regional experiments is provided in Figure 14, which shows scatterplots of the dynamical and thermodynamical components of the moisture transport vs. the total transport, in our selected key regions (see legend).

In the equatorial region, dynamical changes (i.e. increased wind convergence) are almost entirely responsible for the projected increased rainfall in CMIP5 models (black and gray dots in Fig. 14a,b). The same processes control the south central Pacific drying (Fig. 14c,d). In the southwest Pacific (Fig. 14e,f), there tends to be a cancellation between dynamical processes that tend to induce a drying through increased wind divergence and thermodynamical processes that increase moisture convergence and rainfall in the CMIP5 models. Depending on the respective contributions from these two processes, CMIP5 models can either display increased or decreased precipitation in the southwest Pacific, resulting in a large spread across models and a nearly-zero ensemble mean projected rainfall change.

The $\mathrm{CMIP}_{\mathrm{ZM}}$ and $\mathrm{CMIP}_{\mathrm{BM}}$ experiments lie at the upper end of the CMIP5 models distribution in both the western equatorial Pacific (blue symbols in Fig. 14a,b) and the south central Pacific (blue symbols in Fig. 14c,d), the dynamical component largely explaining the total changes. Correcting historical and projected CMIP5 SST biases generally leads to an increase of the dynamical response and hence of the rainfall anomaly, this increase being particularly prominent in the western equatorial Pacific for BMJ. In the southwestern Pacific, the drying by dynamical processes is about $\sim 20 \%$ larger in the experiment using the bias-corrected warming pattern (Fig. 14e). On the other hand, the thermodynamical effects are very similar in all our experiments (Fig. 14f), and have similar amplitudes to those in CMIP5 models. This yields a larger southwest Pacific drying in the experiments where the future warming 
of the circulation changes and associated moisture divergence resulting in turn to an underestimation of the southwest Pacific drying.

\section{Summary and discussion}

\subsection{Summary}

This study investigates the influence of anthropogenic forcing on the SPCZ mean state and interannual variability. A present-day simulation $\left(\mathrm{PD}_{-} \mathrm{OBS}_{\mathrm{ZM}}\right.$ ) with a regional atmospheric model captures the main observed SPCZ characteristics, with a similar degree of realism to that of NCEP2 reanalysis. This includes the SPCZ mean state but also its northward/southward displacements associated with ENSO, including the SPCZ zonal events during extreme El Niño events. This accurate present-day simulation of the SPCZ justifies the use of our regional model configuration to assess the SPCZ response to climate change. In contrast, a simulation (PD_CMIP5 $5_{\mathrm{ZM}}$ ) forced by CMIP5 climatological

511 SST (and the trademark cold tongue bias in CMIP models) yields a similar SPCZ bias as in the CMIP5 models, with too zonal a SPCZ.

We further performed three simulations to estimate the influence of climate change: $\mathrm{CC}_{-} \mathrm{CMIP} 5_{\mathrm{ZM}}$, 514 CC_OBS $\mathrm{ZM}$, and $\mathrm{CC}_{-} \mathrm{COR}_{\mathrm{ZM}}$. In $\mathrm{CC}_{-} \mathrm{CMIP}_{\mathrm{ZM}}$ and $\mathrm{CC}_{-} \mathrm{OBS}_{\mathrm{ZM}}$, the projected changes from CMIP5 MMM are added to 515 the boundary conditions used in $\mathrm{PD}_{-} \mathrm{CMIP} 5_{\mathrm{ZM}}$ and $\mathrm{PD}_{-} \mathrm{OBS}_{\mathrm{ZM}}$ experiments respectively. Comparing those two sets of 516 experiments permits assessment of the effect of the SST bias in CMIP5 models. CC_COR ${ }_{Z M}$ simulation is similar to 517 CC_OBS $\mathrm{ZM}$, but the projected SST change from the CMIP5 ensemble mean is additionally corrected using an "emergent 518 constraint" method, based on Li et al. (2016). Comparing this last experiment to CC_OBS $\mathrm{ZM}$ allows for the estimation of 519 the effect of the warming pattern bias on the SPCZ changes.

520 To assess the sensitivity to model physics, we compared the projections from our $\mathrm{CMIP} 5_{\mathrm{ZM}}$ in-house 521 simulations to that of the CMIP5 MMM. The SPCZ response to climate change is slightly more intense in CC_CMIP ${ }_{\mathrm{ZM}}$ 522 than in CMIP5 MMM, with a stronger increase of precipitation in the equatorial region ( $48 \%$ vs $37 \%$ increase) and a 523 stronger drying in the southeastern Pacific $1 \mathrm{~mm}$.day ${ }^{-1}$ compared to $-0.4 \mathrm{~mm} \cdot$ day $^{-1}$ ( $20 \% \mathrm{vs} 7 \%$ decrease), leading to a 524 shrinkage of the SPCZ. Our "CMIP" setup hence reproduces qualitatively the rainfall changes in CMIP5 MMM, but magnifies the amplitude of the precipitation response to anthropogenic forcing.

To evaluate the impact of historical CMIP5 SST biases, we compared the projections derived from CC_OBS $\mathrm{ZM}_{\mathrm{ZM}}$ simulation to that of CC_CMIP $\mathrm{ZM}$. Correcting the CMIP5 historical SST bias leads to a stronger equatorial Pacific rainfall increase in response to climate change ( $66 \%$ vs. $48 \%$ increase), mainly due to a weaker negative feedback of the thermodynamic component of moisture transport in $\mathrm{CC}_{-} \mathrm{OBS}_{\mathrm{ZM}}$. The drying in the southwest Pacific is hardly influenced by the CMIP5 SST bias. These changes are associated with a $\sim 4^{\circ}$ southward shift of the mean SPCZ location west of $170^{\circ} \mathrm{W}$ in CC_OBS $\mathrm{ZM}_{\mathrm{zM}}$.

An original aspect of our study is to evaluate the impact of plausible biases in the projected SST pattern simulated by CMIP models, by comparing the projections of CC_COR $\mathrm{ZM}_{\mathrm{ZM}}$ and $\mathrm{CC} \_\mathrm{OBS} \mathrm{ZM}_{\mathrm{ZM}}$. In CC_COR $\mathrm{Z}_{\mathrm{ZM}}$, the equatorial rainfall increase is weaker than in CC_OBS become much drier ( $35 \%$ vs. $15 \%$ rainfall decrease). While the drying was mainly limited to the east of the dateline in 
CC_OBS $\mathrm{ZM}$, it extends farther west to $150^{\circ} \mathrm{E}$ in $\mathrm{CC}_{-} \mathrm{COR}_{\mathrm{ZM}}$, resulting in a $25 \%$ drying in the southwestern Pacific 537 compared to $-1 \%$ in $\mathrm{CC}_{-} \mathrm{OBS}_{\mathrm{ZM}},-7 \%$ in $\mathrm{CC}_{-} \mathrm{CMIP}_{\mathrm{ZM}}$, and $+3 \%$ in CMIP5 MMM. Correcting the projected SSTs

538 changes modifies the SST gradients in the southwestern Pacific, leading to southeasterlies that penetrate farther west 539 and north. This induces more moisture divergence through dynamical processes, and hence a larger drying.

540 All the climate change simulations display enhanced rainfall variability in the equatorial region, but this 541 change is not the same across ENSO phases. The precipitation increase is strongest during extreme El Niño events, 542 illustrating the non-linearity of the precipitation response to climate change during ENSO phases, as in the idealized 543 framework of Chung et al. (2014). Our analyses show that the number of SPCZ zonal events under climate change 544 conditions remains similar to the present-day conditions in all our simulations even with weakened SST meridional 545 gradients, in contrast with the result of Cai et al. (2012) based on CMIP3-5 models, questioning the actual mechanisms 546 underlying such changes.

Last but not least, additional regional simulations using a completely different set of physical 548 parameterizations give qualitatively similar results for the future SPCZ mean change and on how these patterns are 549 influenced by CMIP present and future biases, underlining the robustness of our results.

\subsection{Discussion}

Several studies have already investigated the impact of climate change on the mean SPCZ climate, either by directly comparing global coupled climate models (Brown et al. 2012, 2013) or by comparing atmospheric experiments forced with and without climate change boundary condition anomalies (Widlanky et al. 2013; Brown et al. 2015; Evans et al. 2016). A direct analysis of CMIP5 model outputs reveals that the climate change results in a robust precipitation increase in the equatorial Pacific (e.g. Watanabe et al. 2014; Li et al. 2016), a weak drying of the southeast SPCZ margin in the CMIP5 models but no consistent shift in climatological SPCZ position (Brown et al. 2012, 2013). Despite stronger rainfall change in our sets of experiments than in CMIP5 MMM, we find that the increased equatorial rainfall and dryer eastern SPCZ are robust features. On the other hand, CMIP5 MMM, our CC_OBS and CC_CMIP5 simulations show a weak and largely insignificant drying in the western SPCZ part, while, by contrast, our CC_COR simulations yield a strong significant drying in this region in both $\mathrm{ZM}$ an BMJ configurations (25\% and $18 \%$ respectively).

Our results in the OBS experiments are in qualitative agreement with the atmospheric experiments of 564 Widlansky et al. (2013). Indeed, their present-day SST bias-corrected simulations pointed toward a significant drying of the SPCZ and wetter equatorial Pacific conditions during austral summer. In contrast, results from the bias-corrected experiments from Brown et al. (2015) still indicate a future wettening of the southwest Pacific. We suggest that our results are more reliable than those of Brown et al. (2015), due to a more realistic experimental strategy. Indeed, Brown 568 et al. (2015) used an idealized framework by forcing their atmospheric model with annually averaged SST, which may 569 have impaired the realism of their projected rainfall response. As acknowledged by these authors, their objective was not to provide a reliable projection of future rainfall but rather to demonstrate the sensitivity of the rainfall response to

571 the underlying SST patterns. Evans et al. (2016) also used a present-day SST bias-corrected strategy, with several 572 regional climate models forced by the same CMIP global warming anomalous pattern. While they showed that their 573 projected rainfall response was not very sensitive to the choice of the CMIP model used to force their regional model 
boundaries, their projections in the southwest Pacific region were more sensitive to the parameterizations used in their regional model. Despite this sensitivity, they indicated that the majority of their configurations ( 7 out of 9) projected a significant drying of the southwest Pacific, in line with Widlansky et al. (2013) and the present study.

In our COR experiment, we have tested the sensitivity of the rainfall response to the characteristics of the projected SST pattern. Brown et al. (2015) suggested that the amplitude of the rainfall response could be highly sensitive to the pattern of SST warming. Huang and Ying (2015) and Li et al. (2016) confirmed that the well-known cold tongue bias in most CMIP models could lead to an underestimation in the zonal gradient of the projected sea surface warming along the equator. In contrast, Widlansky et al. (2013) argued that the SST warming pattern was independent of the climatological SST bias by comparing the SST warming pattern from a climate model run with and without flux adjustment strategy. In line with the previous statistical studies (Huang and Ying, 2015; Li et al. 2016), we find that biases in CMIP5 SST warming pattern considerably influence the future changes of regional precipitations. Future precipitation changes in the western tropical Pacific are indeed driven by two main processes, which respective contributions are strongly influenced by the underlying background SSTs: a "wet gets wetter" thermodynamic response and a "warmest gets wetter" dynamical response due to the overall tropical circulation slowdown (Widlansky et al. 2013).

Despite the absence of consensus on how SST variability associated with ENSO may change in the future (e.g. Cai et al. 2015), CMIP3-5 models project a future increase in the frequency of zonal SPCZ events, which has been attributed to mean changes in meridional SST gradient between the equator and the South Pacific (Cai et al. 2012). In line with recent studies using similar experimental strategy (Chung and Power 2016; Evans et al. 2016), our results suggest that the frequency of zonal SPCZ events may not increase in the future, in contradiction to the results of Cai et al. (2012). As already pointed out by Chung and Power (2016), several reasons could explain this apparent discrepancy. First, the present and future SST variability is kept constant in our simulations: it may well be that, in contradiction to what has been initially proposed by Cai et al. (2012), the mean meridional gradient SST changes may not be the dominant mechanism explaining the zonal SPCZ events frequency increase in their study. Rather, consistent changes in SST interannual variability in CMIP models or changes in weather variability such as the atmospheric Rossby wave forcing could be partly responsible for this increase. Other hypotheses explaining this discrepancy also include the diversity of the warming patterns across the CMIP5 models, not taken into account in our CMIP5 MMM warming pattern set-up, the lack of atmosphere-ocean feedbacks in our forced atmospheric simulations compared to CMIP models.

In any case, this study highlights the importance of better understanding the role of tropical Pacific SST biases and their likely-biased projections for reliable projections. While a long-term objective is clearly to reduce longstanding robust SST biases in the tropical Pacific in CMIP models, this study also advocates for a shorter-term strategy, by using stand-alone atmospheric experiments where present-day and future SST projection are bias-corrected. This study also highlights the need to apply this kind of strategy with different models: while the bias correction approach used in this forced atmospheric study is likely to improve the reliability of future projection, AMIP-type simulations still exhibit significant biases in their representation of the present-day SPCZ characteristics (Lintner et al., 2016), which may still impair the reliability of the projected changes, as illustrated here by the significant quantitative differences in the projected rainfall changes in our two model configurations (Fig. 7d vs. Fig. 13a). The choice of the reanalysis products used to build the boundaries conditions (NCEP 2 in this paper) may also influence the projected 
SPCZ changes, since the present-day representation of SPCZ characteristics differ between reanalyses products (e.g,

615 Niznik et al. 2013). Finally, the sensitivity of the projected changes to the statistical correction method used to correct

616 the projected SST changes should also be tested. Instead of using a statistical correction based on the western Pacific 617 rainfall bias as in Li et al. (2016), a correction based on the amplitude of the cold tongue bias should also be tested. In 618 addition, results with the simple statistical correction strategy proposed by Li et al. (2016) should also be compared with 619 more complex strategies, such as the one proposed by Huang and Ying (2015), which extracts the leading bias modes of 620 historical SST in CMIP5 and then projecting the tropical Pacific SST changes onto these historical bias modes.

\section{References :}

Alexander, L.V. Zhang, X. Peterson, T.C. Caesar, J. Gleason, B. Klein Tank, A.M.G. Haylock, M. Collins, D. Trewin, B. Rahimzadeh, F. et al. (2006). Global observed changes in daily climate extremes of temperature and precipitation. J. Geophys. Res. 111.

Bellenger, H. Guilyardi, E. Leloup, J. Lengaigne, M. and Vialard, J. (2014). ENSO representation in climate models: from CMIP3 to CMIP5. Clim. Dyn. 42, 1999-2018.

Bracegirdle, T.J. and Stephenson, D.B. (2013). On the Robustness of Emergent Constraints Used in Multimodel Climate Change Projections of Arctic Warming. J. Clim. 26, 669-678.

Bretherton, C.S. and Park, S. (2009). A New Moist Turbulence Parameterization in the Community Atmosphere Model. J. Clim. 22, 3422-3448.

Brown, J.N. Matear, R.J. Brown, J.R. and Katzfey, J. (2015). Precipitation projections in the tropical Pacific are sensitive to different types of SST bias adjustment: precipitation and SST bias adjustment. Geophys. Res. Lett. 42, $10,856-10,866$.

Brown, J.R. Power, S.B. Delage, F.P. Colman, R.A. Moise, A.F. and Murphy, B.F. (2011). Evaluation of the South Pacific Convergence Zone in IPCC AR4 Climate Model Simulations of the Twentieth Century. J. Clim. 24, 1565-1582.

Brown, J.R. Moise, A.F. and Delage, F.P. (2012). Changes in the South Pacific Convergence Zone in IPCC AR4 future climate projections. Clim. Dyn. 39, 1-19.

Brown, J.R. Moise, A.F. and Colman, R.A. (2013). The South Pacific Convergence Zone in CMIP5 simulations of historical and future climate. Clim. Dyn. 41, 2179-2197.

Cai, W. Lengaigne, M. Borlace, S. Collins, M. Cowan, T. McPhaden, M.J. Timmermann, A. Power, S. Brown, J. Menkes, C. et al. (2012). More extreme swings of the South Pacific convergence zone due to greenhouse warming. Nature 488, 365-369.

Cai, W. Borlace, S. Lengaigne, M. van Rensch, P. Collins, M. Vecchi, G. Timmermann, A. Santoso, A. McPhaden, M.J. $\mathrm{Wu}, \mathrm{L}$. et al. (2014). Increasing frequency of extreme El Niño events due to greenhouse warming. Nat. Clim. Change 4, $111-116$.

Cai, W. Santoso, A. Wang, G. Yeh, S.-W. An, S.-I. Cobb, K.M. Collins, M. Guilyardi, E. Jin, F.-F. Kug, J.-S. et al. (2015). ENSO and greenhouse warming. Nat. Clim. Change 5, 849-859.

Chen, F. and Dudhia, J. (2001). Coupling an Advanced Land Surface-Hydrology Model with the Penn State-NCAR MM5 Modeling System. Part I: Model Implementation and Sensitivity. Mon. Weather Rev. 129, 569-585.

Chung, C.T.Y. and Power, S.B. (2016). Modelled impact of global warming on ENSO-driven precipitation changes in the tropical Pacific. Clim. Dyn. 47, 1303-1323.

Chung, C.T.Y. Power, S.B. Arblaster, J.M. Rashid, H.A. and Roff, G.L. (2014). Nonlinear precipitation response to El Niño and global warming in the Indo-Pacific. Clim. Dyn. 42, 1837-1856. 
Collins, M. An, S.-I. Cai, W. Ganachaud, A. Guilyardi, E. Jin, F.-F. Jochum, M. Lengaigne, M. Power, S. Timmermann, A. et al. (2010). The impact of global warming on the tropical Pacific Ocean and El Niño. Nat. Geosci. 3, $391-397$.

Collins, W.D. Rasch, P.J. Boville, B.A. Hack, J.J. McCaa, J.R. Williamson, D.L. Kiehl, J.T. Briegleb, B. Bitz, C. Lin, S.-J. et al. (2004). Description of the NCAR Community Atmosphere Model (CAM 3.0). 226.

Deser, C. Phillips, A.S. and Alexander, M.A. (2010). Twentieth century tropical sea surface temperature trends revisited: twentieth century tropical SST trends. Geophys. Res. Lett. 37, n/a-n/a.

Evans, J.P. Bormann, K. Katzfey, J. Dean, S. and Arritt, R. (2016). Regional climate model projections of the South Pacific Convergence Zone. Clim. Dyn. 47, 817-829.

Folland, C.K. (2002). Relative influences of the Interdecadal Pacific Oscillation and ENSO on the South Pacific Convergence Zone. Geophys. Res. Lett. 29.

Gouriou, Y. and Delcroix, T. (2002). Seasonal and ENSO variations of sea surface salinity and temperature in the South Pacific Convergence Zone during 1976-2000: sea surface salinity and temperature in the SPCZ. J. Geophys. Res. Oceans 107, SRF 12-1-SRF 12-14.

Grose, M.R. Brown, J.N. Narsey, S. Brown, J.R. Murphy, B.F. Langlais, C. Gupta, A.S. Moise, A.F. and Irving, D.B. (2014). Assessment of the CMIP5 global climate model simulations of the western tropical Pacific climate system and comparison to CMIP3: assesment of CMIP5 climate models for the western tropical pacific. Int. J. Climatol. 34, 33823399 .

Held, I.M. and Soden, B.J. (2006). Robust Responses of the Hydrological Cycle to Global Warming. J. Clim. 19, 56865699 .

Herger, N., Abramowitz, G., Knutti, R., Angélil, O., Lehmann, K. and Sanderson, B. M.: Selecting a climate model subset to optimise key ensemble properties, Earth System Dynamics, 9(1), 135-151, doi:10.5194/esd-9-135-2018, 2018.

Hong, S.-Y. Dudhia, J. and Chen, S.-H. (2004). A Revised Approach to Ice Microphysical Processes for the Bulk Parameterization of Clouds and Precipitation. Mon. Weather Rev. 132, 103-120.

Huang, P. and Ying, J. (2015). A Multimodel Ensemble Pattern Regression Method to Correct the Tropical Pacific SST Change Patterns under Global Warming. J. Clim. 28, 4706-4723.

Huang, P. Xie, S.-P. Hu, K. Huang, G. and Huang, R. (2013). Patterns of the seasonal response of tropical rainfall to global warming. Nat. Geosci. 6, 357-361.

Iacono, M.J. Delamere, J.S. Mlawer, E.J. Shephard, M.W. Clough, S.A. and Collins, W.D. (2008). Radiative forcing by long-lived greenhouse gases: Calculations with the AER radiative transfer models. J. Geophys. Res. 113.

Irving, D. Perkins, S. Brown, J. Sen Gupta, A. Moise, A. Murphy, B. Muir, L. Colman, R. Power, S. Delage, F. et al. (2011). Evaluating global climate models for the Pacific island region. Clim. Res. 49, 169-187.

Janjić, Z.I. (1994). The Step-Mountain Eta Coordinate Model: Further Developments of the Convection, Viscous Sublayer, and Turbulence Closure Schemes. Mon. Weather Rev. 122, 927-945.

Jourdain, N.C. Marchesiello, P. Menkes, C.E. Lefèvre, J. Vincent, E.M. Lengaigne, M. and Chauvin, F. (2011). Mesoscale Simulation of Tropical Cyclones in the South Pacific: Climatology and Interannual Variability. J. Clim. 24, 3-25.

Juillet-Leclerc, A. Thiria, S. Naveau, P. Delcroix, T. Le Bec, N. Blamart, D. and Corrège, T. (2006). SPCZ migration and ENSO events during the 20th century as revealed by climate proxies from a Fiji coral. Geophys. Res. Lett. 33.

Jullien, S. Marchesiello, P. Menkes, C.E. Lef?vre, J. Jourdain, N.C. Samson, G. and Lengaigne, M. (2014). Ocean feedback to tropical cyclones: climatology and processes. Clim. Dyn. 43, 2831-2854. 
Kanamitsu, M. Ebisuzaki, W. Woollen, J. Yang, S.-K. Hnilo, J.J. Fiorino, M. and Potter, G.L. (2002). NCEP-DOE AMIP-II Reanalysis (R-2). Bull. Am. Meteorol. Soc. 83, 1631-1643.

Kidwell, A. Lee, T. Jo, Y.-H. and Yan, X.-H. (2016). Characterization of the Variability of the South Pacific Convergence Zone Using Satellite and Reanalysis Wind Products. J. Clim. 29, 1717-1732.

Kiladis, G.N. von Storch, H. and Loon, H. (1989). Origin of the South Pacific Convergence Zone. J. Clim. 2, 11851195.

Kirono, D.G.C. Kent, D.M. Hennessy, K.J. and Mpelasoka, F. (2011). Characteristics of Australian droughts under enhanced greenhouse conditions: Results from 14 global climate models. J. Arid Environ. 75, 566-575.

Knutti, R., Furrer, R., Tebaldi, C., Cermak, J. and Meehl, G. A.: Challenges in Combining Projections from Multiple Climate Models, Journal of Climate, 23(10), 2739-2758, doi:10.1175/2009JCLI3361.1, 2010.

Knutti, R., Sedláček, J., Sanderson, B. M., Lorenz, R., Fischer, E. M. and Eyring, V.: A climate model projection weighting scheme accounting for performance and interdependence, Geophysical Research Letters, 44(4), 1909-1918, doi:10.1002/2016GL072012, 2017.

Knutson, T.R. Sirutis, J.J. Garner, S.T. Vecchi, G.A. and Held, I.M. (2008). Simulated reduction in Atlantic hurricane frequency under twenty-first-century warming conditions. Nat. Geosci. 1, 359-364.

Lefèvre, J. Menkes, C. Bani, P. Marchesiello, P. Curci, G. Grell, G.A. and Frouin, R. (2016). Distribution of sulfur aerosol precursors in the SPCZ released by continuous volcanic degassing at Ambrym, Vanuatu. J. Volcanol. Geotherm. Res. 322, 76-104.

Li, G. and Xie, S.-P. (2014). Tropical Biases in CMIP5 Multimodel Ensemble: The Excessive Equatorial Pacific Cold Tongue and Double ITCZ Problems*. J. Clim. 27, 1765-1780.

Li, G. Du, Y. Xu, H. and Ren, B. (2015). An Intermodel Approach to Identify the Source of Excessive Equatorial Pacific Cold Tongue in CMIP5 Models and Uncertainty in Observational Datasets. J. Clim. 28, 7630-7640.

Li, G. Xie, S.-P. Du, Y. and Luo, Y. (2016). Effects of excessive equatorial cold tongue bias on the projections of tropical Pacific climate change. Part I: the warming pattern in CMIP5 multi-model ensemble. Clim. Dyn. 47, 38173831.

Lin, Y.-L. Farley, R.D. and Orville, H.D. (1983). Bulk Parameterization of the Snow Field in a Cloud Model. J. Clim. Appl. Meteorol. 22, 1065-1092.

Lintner, B. R., Langenbrunner, B., Neelin, J. D., Anderson, B. T., Niznik, M. J., Li, G. and Xie, S.-P.: Characterizing CMIP5 model spread in simulated rainfall in the Pacific Intertropical Convergence and South Pacific Convergence Zones, Journal of Geophysical Research: Atmospheres, 121(19), 11,590-11,607, doi:10.1002/2016JD025284, 2016.

Matsueda, M. and Palmer, T.N. (2011). Accuracy of climate change predictions using high resolution simulations as surrogates of truth: accuracy of climate change predictions. Geophys. Res. Lett. 38, n/a-n/a.

Matthews, A. J.: A multiscale framework for the origin and variability of the South Pacific Convergence Zone, Quarterly Journal of the Royal Meteorological Society, 138(666), 1165-1178, doi:10.1002/qj.1870, 2012.

McGree, S. Whan, K. Jones, D. Alexander, L.V. Imielska, A. Diamond, H. Ene, E. Finaulahi, S. Inape, K. Jacklick, L. et al. (2014). An updated assessment of trends and variability in total and extreme rainfall in the western Pacific: trends and variability in extreme rainfall in the western pacific. Int. J. Climatol. 34, 2775-2791.

Mechoso, C.R. Robertson, A.W. Barth, N. Davey, M.K. Delecluse, P. Gent, P.R. Ineson, S. Kirtman, B. Latif, M. Treut, H.L. et al. (1995). The Seasonal Cycle over the Tropical Pacific in Coupled Ocean-Atmosphere General Circulation Models. Mon. Weather Rev. 123, 2825-2838. 
Meehl, G.A. Covey, C. Taylor, K.E. Delworth, T. Stouffer, R.J. Latif, M. McAvaney, B. and Mitchell, J.F.B. (2007). THE WCRP CMIP3 Multimodel Dataset: A New Era in Climate Change Research. Bull. Am. Meteorol. Soc. 88, 13831394.

Meng, Q. Latif, M. Park, W. Keenlyside, N.S. Semenov, V.A. and Martin, T. (2012). Twentieth century Walker Circulation change: data analysis and model experiments. Clim. Dyn. 38, 1757-1773.

Murphy, B.F. Ye, H. and Delage, F. (2015). Impacts of variations in the strength and structure of El Niño events on Pacific rainfall in CMIP5 models. Clim. Dyn. 44, 3171-3186.

Nguyen, K.C. Katzfey, J.J. and McGregor, J.L. (2012). Global 60 km simulations with CCAM: evaluation over the tropics. Clim. Dyn. 39, 637-654.

Niznik, M.J. Lintner, B.R. Matthews, A.J. and Widlansky, M.J. (2015). The Role of Tropical-Extratropical Interaction and Synoptic Variability in Maintaining the South Pacific Convergence Zone in CMIP5 Models. J. Clim. 28, 33533374 .

Noh, Y. Cheon, W.G. Hong, S.Y. and Raasch, S. (2003). Improvement of the K-profile model for the planetary boundary layer based on large eddy simulation data. Bound.-Layer Meteorol. 107, 401-427.

Parvathi, V. Suresh, I. Lengaigne, M. Izumo, T. and Vialard, J. (2017). Robust Projected Weakening of Winter Monsoon Winds Over the Arabian Sea Under Climate Change. Geophys. Res. Lett. 44, 9833-9843.

Perkins, S.E. (2011). Biases and Model Agreement in Projections of Climate Extremes over the Tropical Pacific. Earth Interact. $15,1-36$.

Power, S. Delage, F. Chung, C. Kociuba, G. and Keay, K. (2013). Robust twenty-first-century projections of El Niño and related precipitation variability. Nature 502, 541-545.

Santoso, A., Mcphaden, M. J. and Cai, W.: The Defining Characteristics of ENSO Extremes and the Strong 2015/2016 El Niño: ENSO Extremes, Reviews of Geophysics, 55(4), 1079-1129, doi:10.1002/2017RG000560, 2017.

Skamarock, W.C. and Klemp, J.B. (2008). A time-split nonhydrostatic atmospheric model for weather research and forecasting applications. J. Comput. Phys. 227, 3465-3485.

Solomon, A. and Newman, M. (2012). Reconciling disparate twentieth-century Indo-Pacific ocean temperature trends in the instrumental record. Nat. Clim. Change 2, 691-699.

Taylor, K.E. Stouffer, R.J. and Meehl, G.A. (2012). An Overview of CMIP5 and the Experiment Design. Bull. Am. Meteorol. Soc. 93, 485-498.

Timmermann, A., An, S.-I., Kug, J.-S., Jin, F.-F., Cai, W., Capotondi, A., Cobb, K., Lengaigne, M., McPhaden, M. J., Stuecker, M. F., Stein, K., Wittenberg, A. T., Yun, K.-S., Bayr, T., Chen, H.-C., Chikamoto, Y., Dewitte, B., Dommenget, D., Grothe, P., Guilyardi, E., Ham, Y.-G., Hayashi, M., Ineson, S., Kang, D., Kim, S., Kim, W., Lee, J.-Y., Li, T., Luo, J.-J., McGregor, S., Planton, Y., Power, S., Rashid, H., Ren, H.-L., Santoso, A., Takahashi, K., Todd, A., Wang, G., Wang, G., Xie, R., Yang, W.-H., Yeh, S.-W., Yoon, J., Zeller, E. and Zhang, X.: El Niño-Southern Oscillation complexity, Nature, 559(7715), 535-545, doi:10.1038/s41586-018-0252-6, 2018.

Tokinaga, H. Xie, S.-P. Deser, C. Kosaka, Y. and Okumura, Y.M. (2012). Slowdown of the Walker circulation driven by tropical Indo-Pacific warming. Nature 491, 439-443.

Trenberth, K.E. (1976). Spatial and temporal variations of the Southern Oscillation. Q. J. R. Meteorol. Soc. 102, 639653.

van der Wiel, K., Matthews, A. J., Stevens, D. P. and Joshi, M. M.: A dynamical framework for the origin of the diagonal South Pacific and South Atlantic Convergence Zones, Quarterly Journal of the Royal Meteorological Society, 141(691), 1997-2010, doi:10.1002/qj.2508, 2015. 
van der Wiel, K., Matthews, A. J., Joshi, M. M. and Stevens, D. P.: Why the South Pacific Convergence Zone is diagonal, Climate Dynamics, 46(5-6), 1683-1698, doi:10.1007/s00382-015-2668-0, 2016a.

van der Wiel, K., Matthews, A. J., Joshi, M. M. and Stevens, D. P.: The influence of diabatic heating in the South Pacific Convergence Zone on Rossby wave propagation and the mean flow: The Influence of Diabatic Heating in the SPCZ on Rossby Wave Propagation and the Mean Flow, Quarterly Journal of the Royal Meteorological Society, 142(695), 901-910, doi:10.1002/qj.2692, 2016 b.

van Vuuren, D. P. and Coauthors, 2011: The representative concentration pathways: An overview. Climatic Change, 109, 5-31, https://doi.org/10.1007/s10584-011-0148-z.

Vecchi, G.A. Clement, A. and Soden, B.J. (2008). Examining the tropical Pacific's response to global warming. Eos Trans. Am. Geophys. Union 89, 81-83.

Vincent, D.G. (1994). The South Pacific Convergence Zone (SPCZ): A Review. Mon. Weather Rev. 122, $1949-1970$.

Vincent, E.M. Lengaigne, M. Menkes, C.E. Jourdain, N.C. Marchesiello, P. and Madec, G. (2011). Interannual variability of the South Pacific Convergence Zone and implications for tropical cyclone genesis. Clim. Dyn. 36, 18811896.

Walsh, K. (2015). Fine resolution simulations of the effect of climate change on tropical cyclones in the South Pacific. Clim. Dyn. 45, 2619-2631.

Watanabe, M. Kamae, Y. and Kimoto, M. (2014). Robust increase of the equatorial Pacific rainfall and its variability in a warmed climate: increasing pacific rainfall variability. Geophys. Res. Lett. 41, 3227-3232.

Widlansky, M. J., Webster, P. J. and Hoyos, C. D.: On the location and orientation of the South Pacific Convergence Zone, Climate Dynamics, 36(3-4), 561-578, doi:10.1007/s00382-010-0871-6, 2011.

Widlansky, M.J. Timmermann, A. Stein, K. McGregor, S. Schneider, N. England, M.H. Lengaigne, M. and Cai, W. (2013). Changes in South Pacific rainfall bands in a warming climate. Nat. Clim. Change 3, 417-423.

Xie, S.-P. Deser, C. Vecchi, G.A. Collins, M. Delworth, T.L. Hall, A. Hawkins, E. Johnson, N.C. Cassou, C. Giannini, A. et al. (2015). Towards predictive understanding of regional climate change. Nat. Clim. Change 5, 921-930.

Zhang, G.J. and McFarlane, N.A. (1995). Sensitivity of climate simulations to the parameterization of cumulus convection in the Canadian climate centre general circulation model. Atmosphere-Ocean 33, 407-446.

Zheng, Y. Lin, J.-L. and Shinoda, T. (2012). The equatorial Pacific cold tongue simulated by IPCC AR4 coupled GCMs: Upper ocean heat budget and feedback analysis: The pacific cold tongue bias analysis. J. Geophys. Res. Oceans 117 , n/a-n/a. 

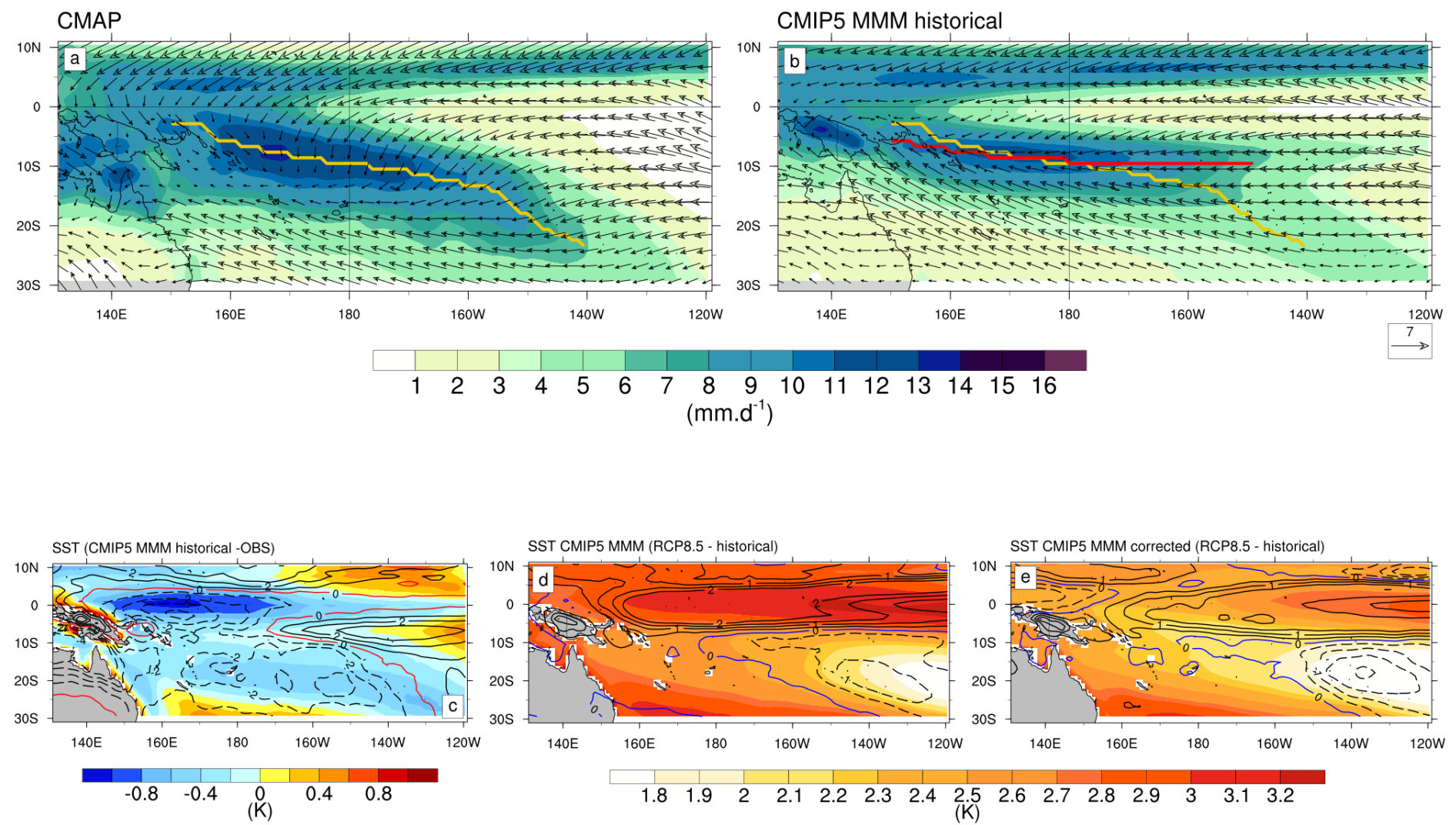

Fig. 1 Top : DJF climatology for precipitation (shading; in mm.day ${ }^{-1}$ ) and near surface wind (vectors; in $\mathrm{m} . \mathrm{s}^{-1}$ ) from (a) CMAP observations, (b) CMIP5 MMM historical. On panel a, near surface wind are taken from NCEP2 reanalysis. On panels a,b, the thick lines (CMAP: yellow, CMIP5 MMM historical: red) represent the mean position of SPCZ.

Bottom : DJF climatology of (in ${ }^{\circ} \mathrm{C}$ ) : (c) historical CMIP5 SST bias, (d) CMIP5 climate change induced SST response, (e) CMIP5 climate change induced SST response corrected from Li et al. (2016). On panels c, d, and e the contours show respectively, the historical CMIP5 rain bias (in mm. $\mathrm{d}^{-1}$ ), the CMIP5 climate change induced rain response, the CMIP5 climate change induced rain response corrected from Li et al. (2016). 


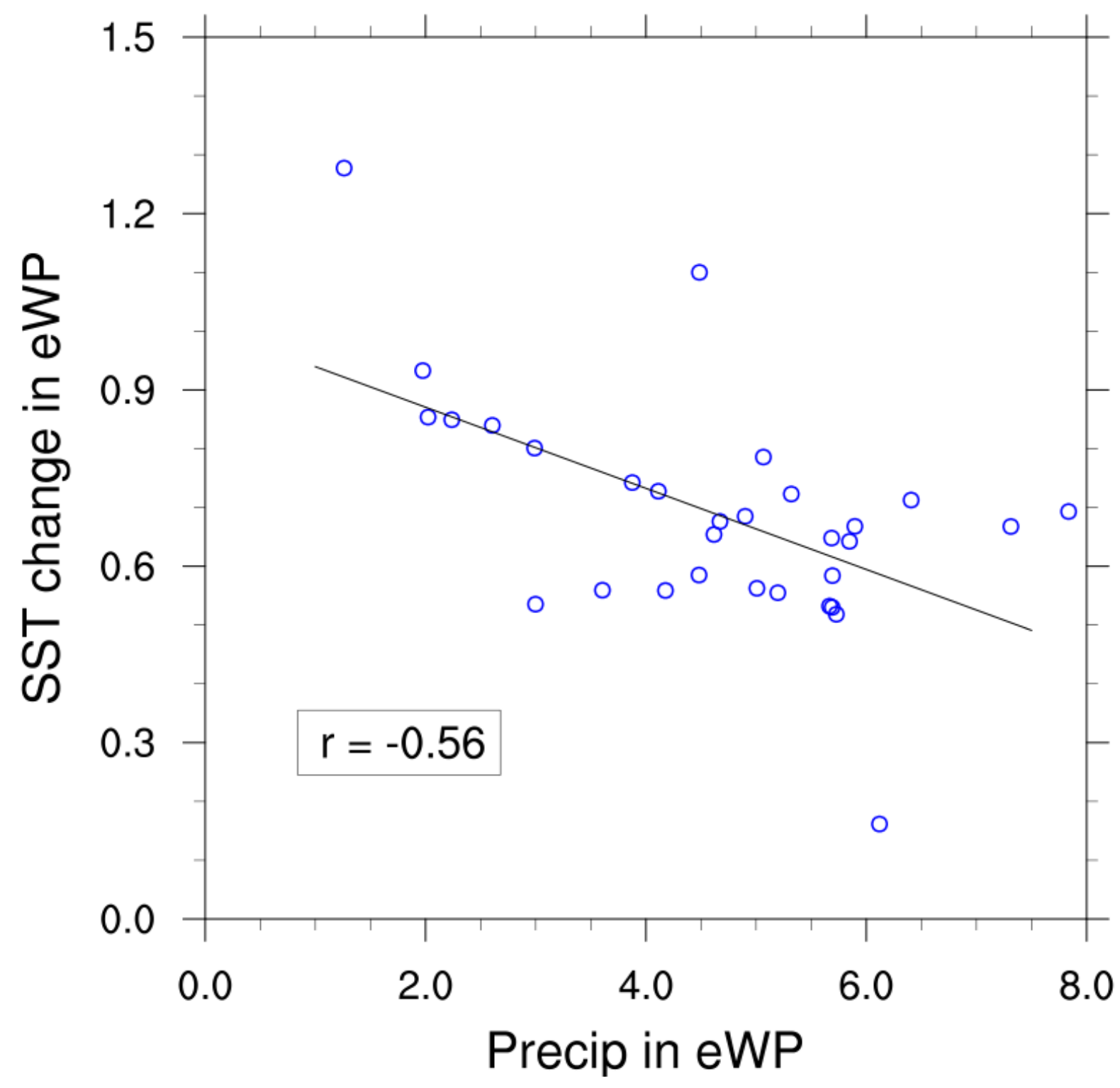

Fig. 2 Relationships between the historical mean precipitation ( $\mathrm{mm} /$ day) and SST projected changes $\left({ }^{\circ} \mathrm{C}\right)$ in the equatorial western Pacific $\left(140^{\circ} \mathrm{E}-190^{\circ} \mathrm{E}\right.$; $2^{\circ} \mathrm{S}-2^{\circ} \mathrm{N}$ ) among $31 \mathrm{CMIP} 5$ models. The inter-model correlation (r) is shown at the bottom-left 

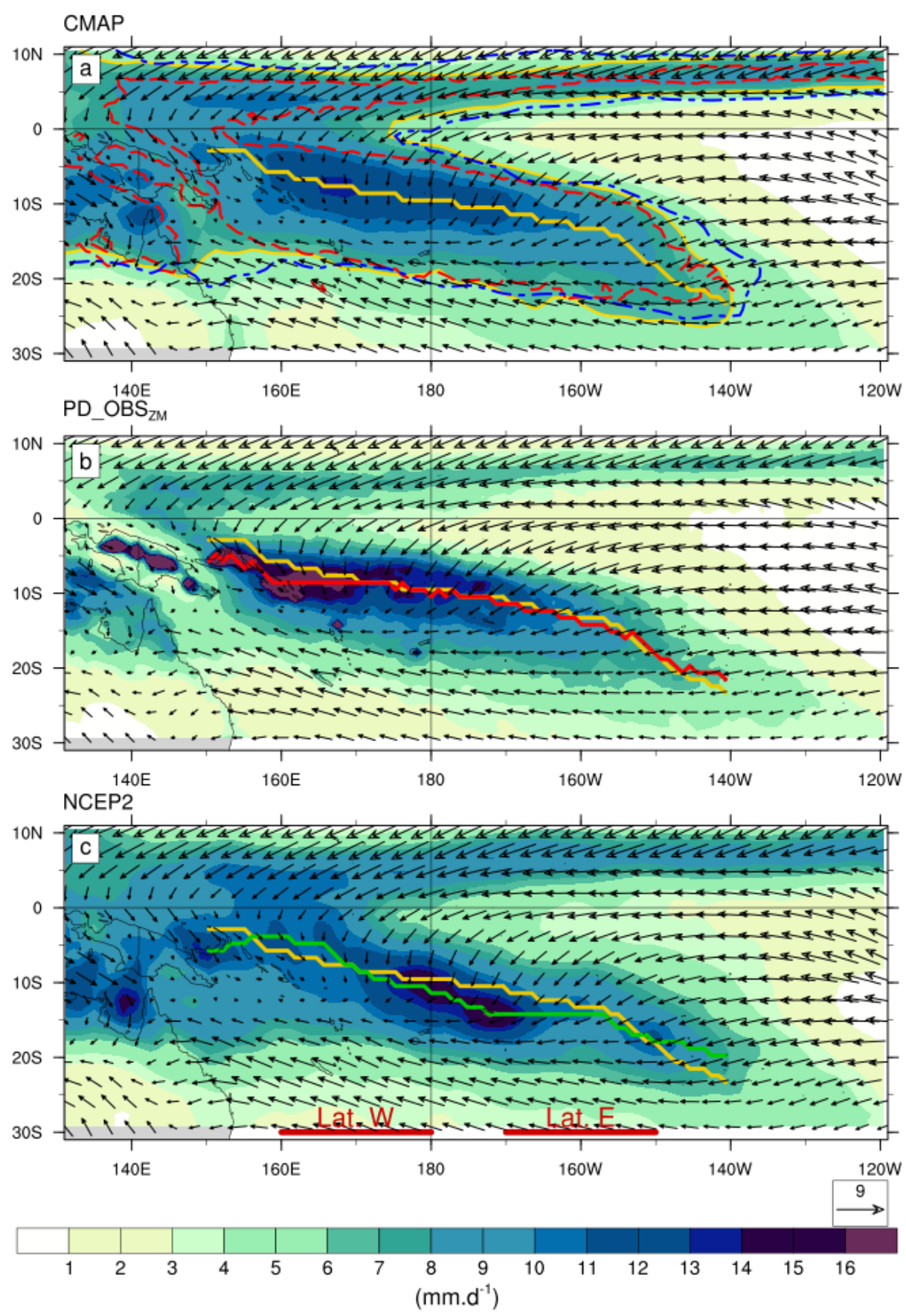

Fig. 3 DJF climatology of precipitation (shading; in mm.day ${ }^{-1}$ ) and near surface wind (vectors; in m. $\mathrm{s}^{-1}$ ) from (a) CMAP observations, (b) PD_OBS ${ }_{\mathrm{ZM}}$ experiment, and (c) NCEP2 reanalysis. Thick lines represent the mean position of SPCZ for CMAP (yellow), PD_OBS ${ }_{Z M}$ experiment (red), NCEP2 reanalysis (blue). On panel a, the thin contours indicate the 6mm.day-1 isopleth for CMAP (yellow), NCEP2 (green), and PD_OBS ${ }_{\text {ZM }}$ experiment (red). On panels a and c, near surface wind are taken from NCEP2 reanalysis. 

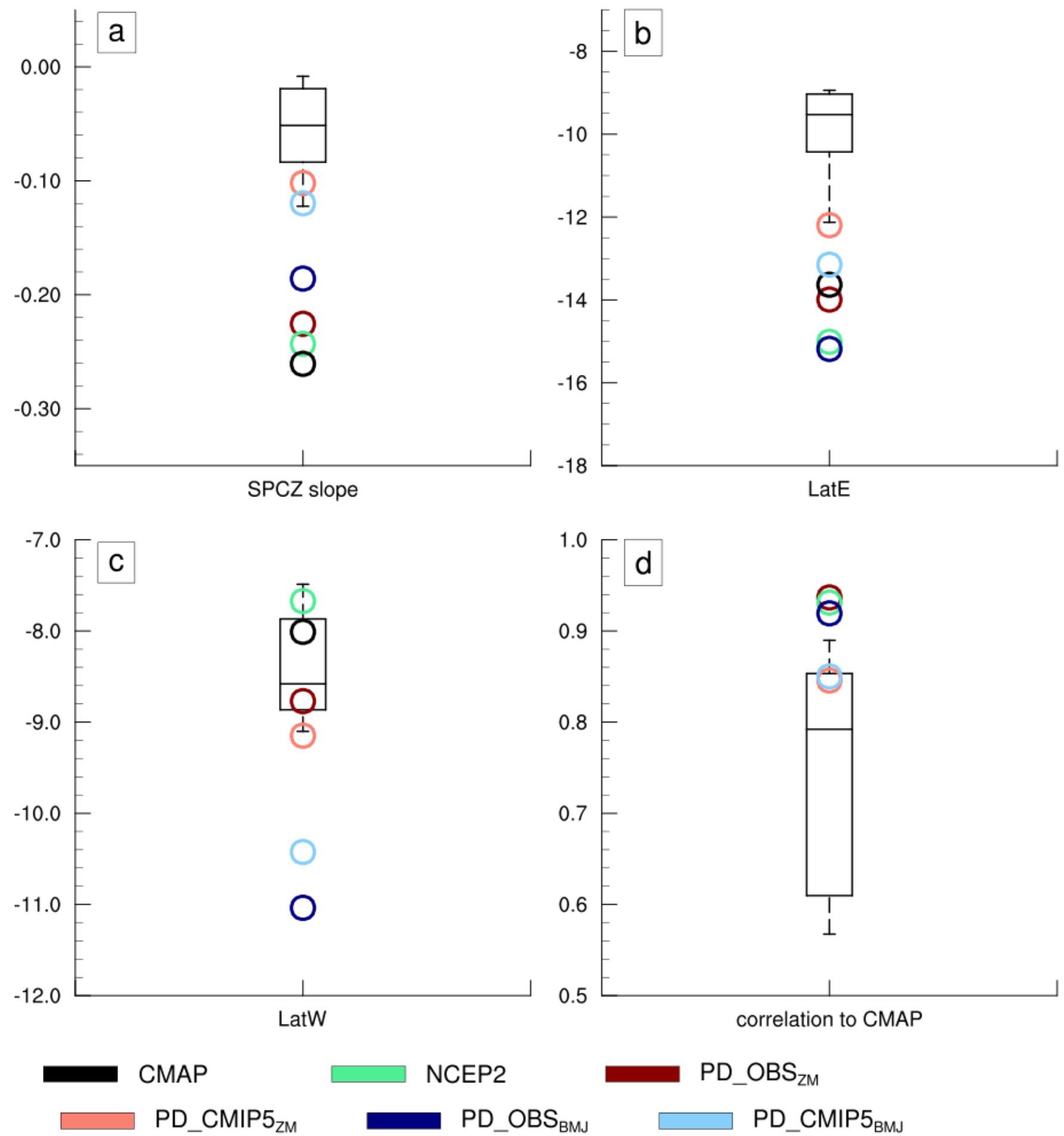

Fig. 4 Evaluation of the SPCZ characteristics in the CMIP5 ensemble over the historical period (box plot showing the median, interquartile range, the first and the last decile values) for CMAP observations (black circle), NCEP2 reanalysis (green circle), $\mathrm{PD}_{-} \mathrm{OBS}_{\mathrm{ZM}}$ simulation (dark red circle), $\mathrm{PD} \_\mathrm{CMIP5}{ }_{\mathrm{ZM}}$ simulation (ligth red circle), $\mathrm{PD}_{-} \mathrm{OBS} \mathrm{BMJ}_{\mathrm{BM}}$ simulation (dark blue circle), $\mathrm{PD}_{-} \mathrm{CMIP5}{ }_{\mathrm{BMJ}}$ simulation (light blue circle). (a) SPCZ slope, (b) SPCZ LatE index, (c) SPCZ LatW index and (d) pattern correlation with DJF climatogical precipitation from CMAP within the $\left[160^{\circ} \mathrm{E}-120^{\circ} \mathrm{W} ; 30^{\circ} \mathrm{S}-0^{\circ}\right]$ region. 

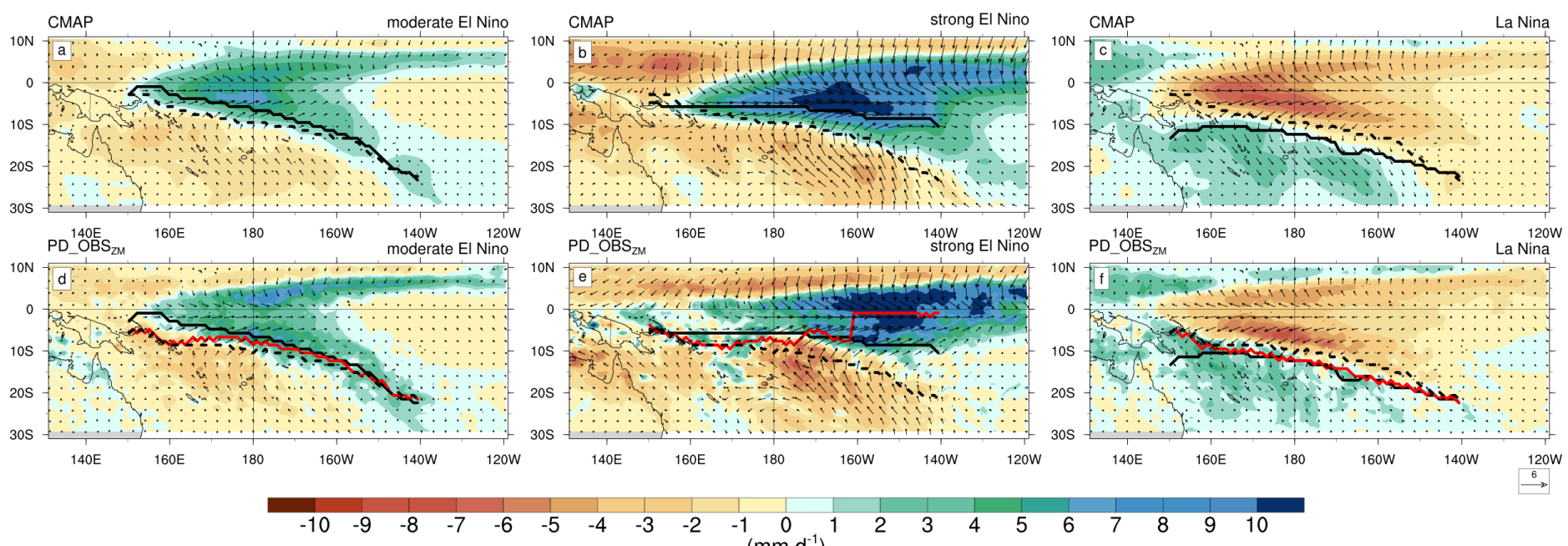

Fig. 5 DJF precipitation anomalies (shading; in mm.day ${ }^{-1}$ ) and near surface wind (vectors; in $\mathrm{m}^{-1} \mathrm{~s}^{-1}$ ) for CMAP (First row), PD_OBS ${ }_{\mathrm{ZM}}$ (second row) and for (left) moderate El Niño, (middle) strong El Niño events and (right) La Nina events. On panels $a, b$ and c, near surface wind are taken from NCEP2 reanalysis. The black (CMAP) and red $\left(\mathrm{PD}_{-} \mathrm{OBS}_{\mathrm{ZM}}\right)$ curves are the ENSO-based composite SPCZ position. The black dashed line shows the climatological SPCZ position. 


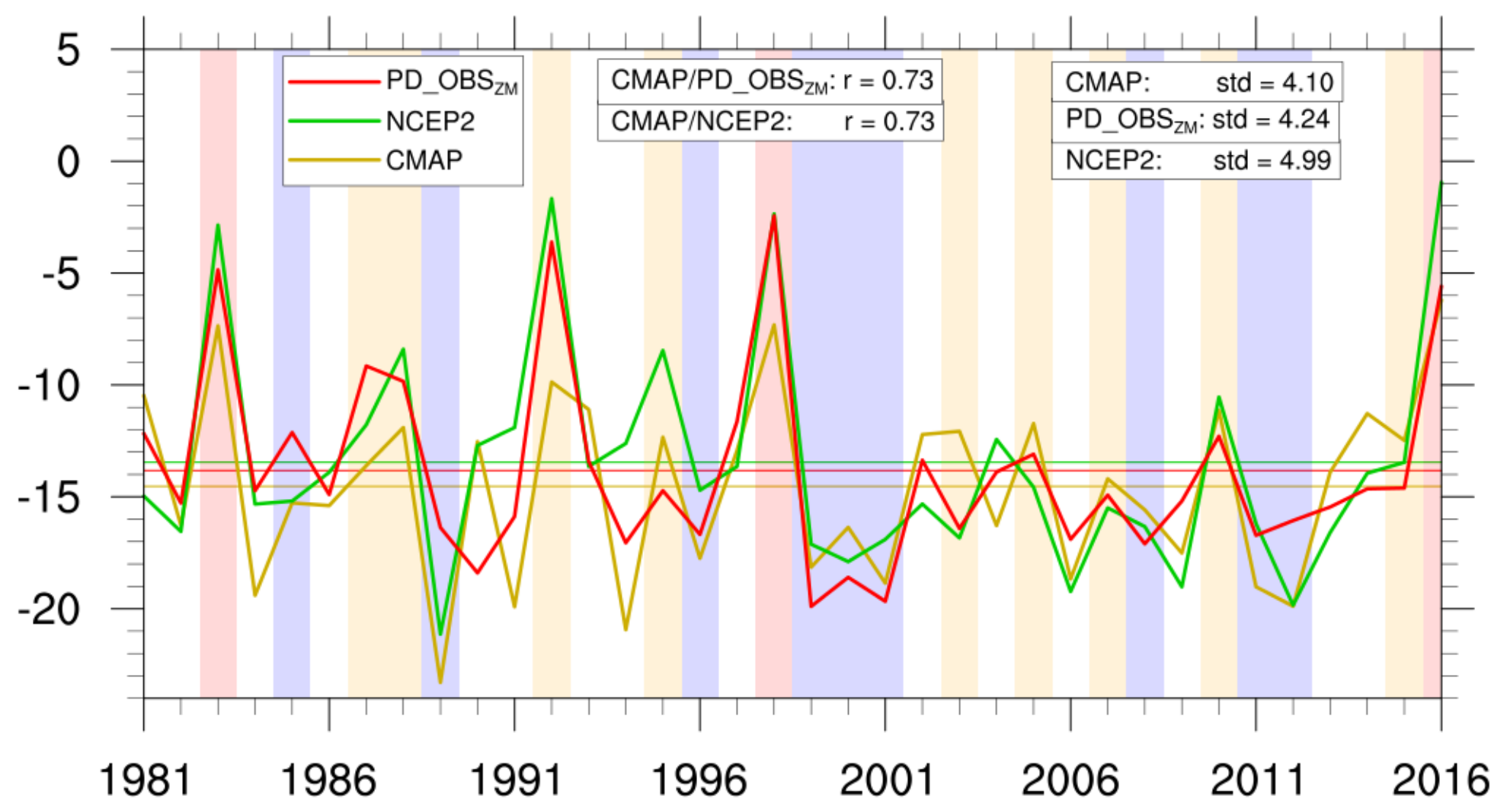

Fig. 6 Evolution of DJF LatE SPCZ index for CMAP (yellow), NCEP2 (green), and PD_OBS ${ }_{\text {ZM }}$ (red). Horizontal lines show the averaged value of the index. The standard deviation (std) and the Pearson correlation (r) are also indicated in the Figure. Vertical colors shadings indicate ENSO phases, moderate El Nino (yellow), La Nina (blue), and strong El Nino (red). 

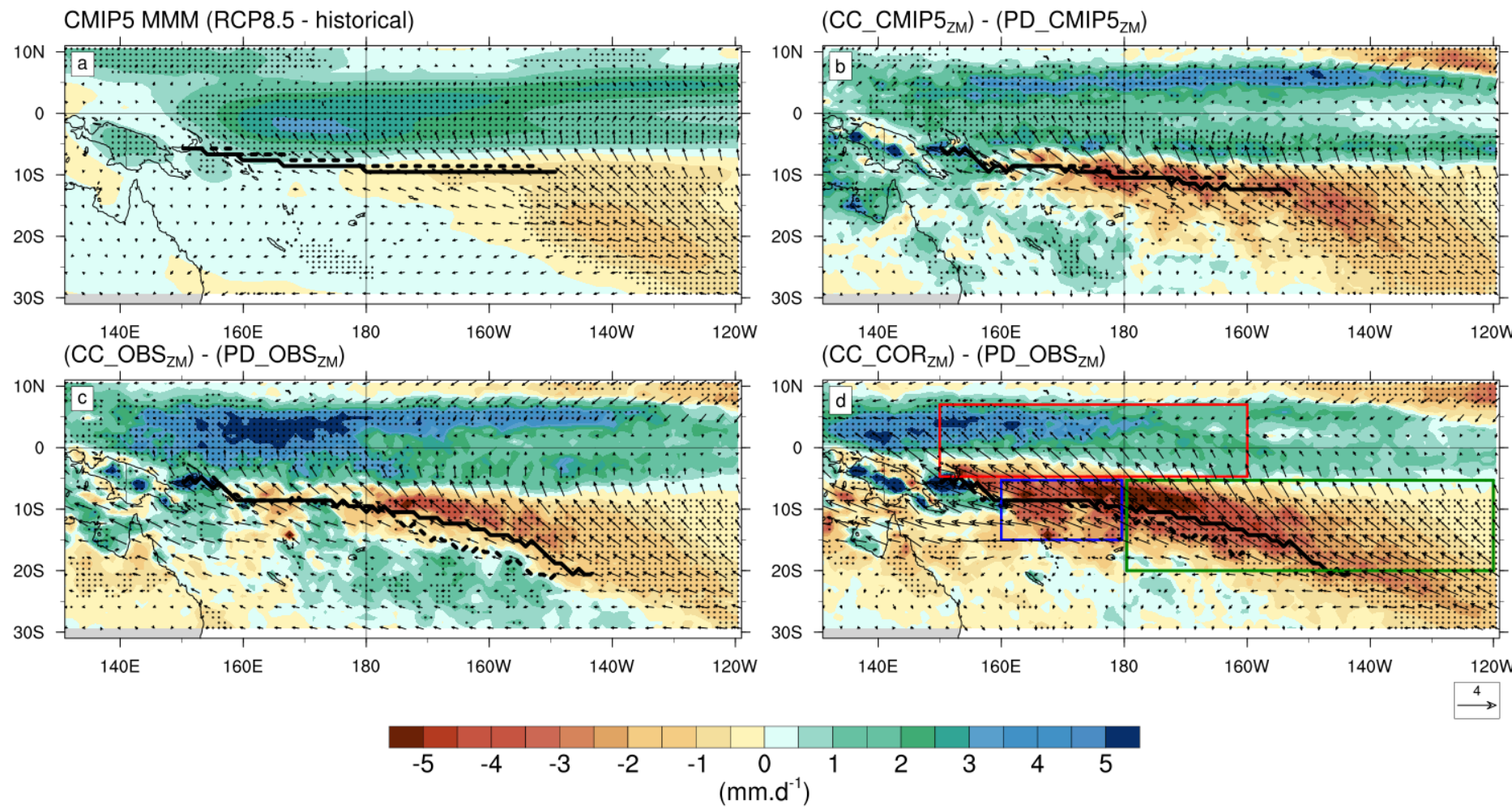

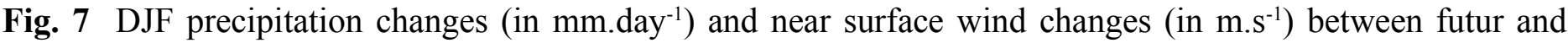
present ; a)CMIP5 MMM, b) CMIP5 ${ }_{\mathrm{ZM}}$, c) $\mathrm{OBS}_{\mathrm{ZM}}$, and d) $\mathrm{COR}_{\mathrm{ZM}}$. The black thick (dashed) lines display the mean position of SPCZ in the present (future) simulation. Regions where the statistical test on the mean is significant at $95 \%$ are stippled. Colored boxes panel in d) denote regions used in Figure 9. 


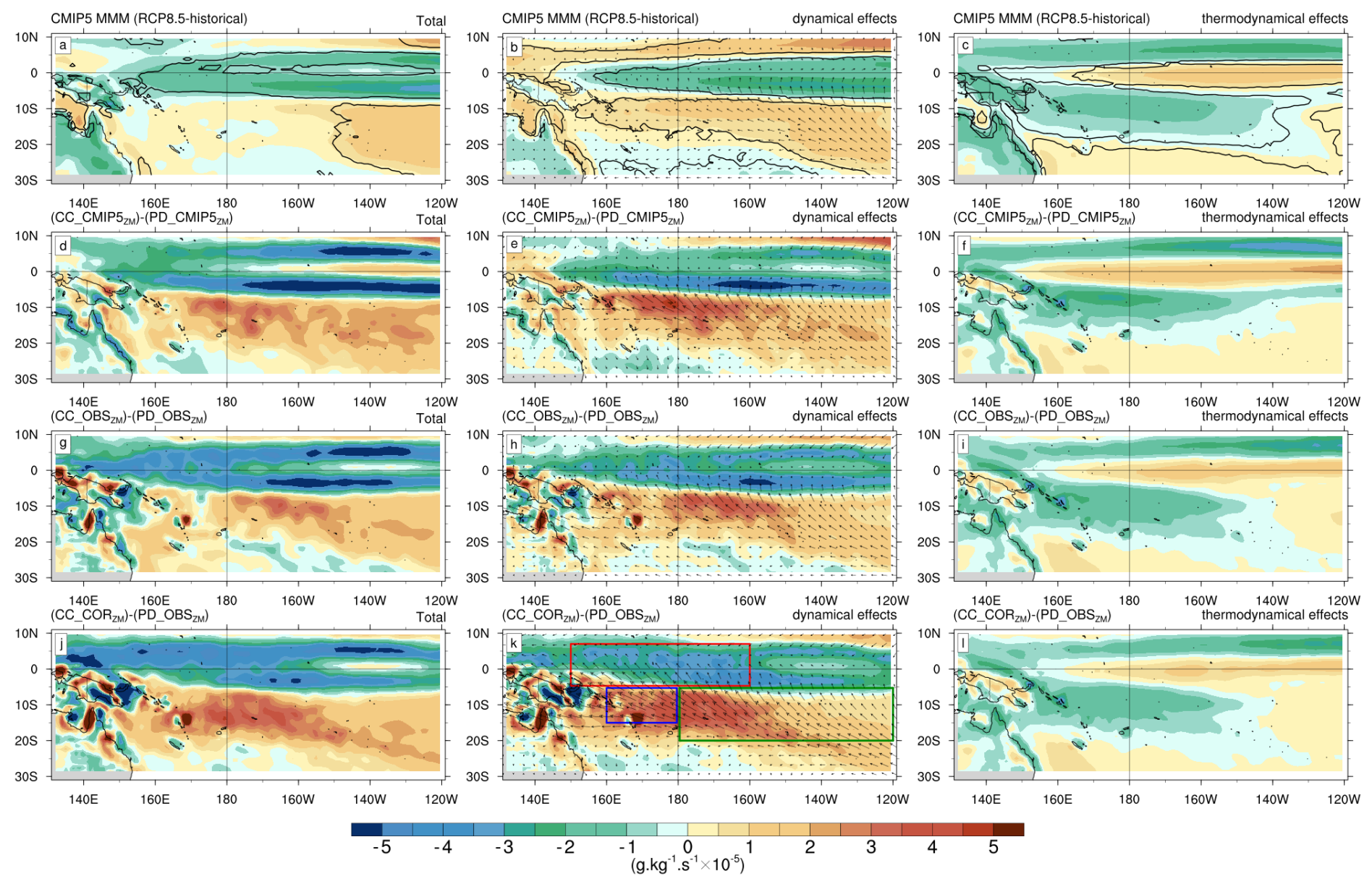

Fig. 8 Total (top), dynamic (middle), and thermodynamic (bottom) effects on the moisture divergence (in g.kg$\left.{ }^{1} \cdot \mathrm{s}^{-1} \times 10^{-5}\right)$ change (future - present) in the $\left(\mathrm{CC}_{-} \mathrm{COR}_{\mathrm{ZM}}\right)-\left(\mathrm{PD}_{-} \mathrm{OBS}_{\mathrm{ZM}}\right)$ simulations (first column), in the $\left(\mathrm{CC}_{-} \mathrm{OBS} \mathrm{ZM}_{\mathrm{ZM}}\right)-\left(\mathrm{PD}_{-} \mathrm{OBS} \mathrm{ZM}_{\mathrm{Z}}\right)$ simulations (second column $),\left(\mathrm{CC}_{-} \mathrm{CMIP} 5_{\mathrm{ZM}}\right)-\left(\mathrm{PD}_{-} \mathrm{CMIP5} \mathrm{ZM}_{\mathrm{ZM}}\right)$ simulations (third column), and CMIP5 MMM (RCP8.5 - historical) (fourth column). Contours denote regions where at least $75 \%$ of the CMIP5 models agree on the sign of the precipitation change. 

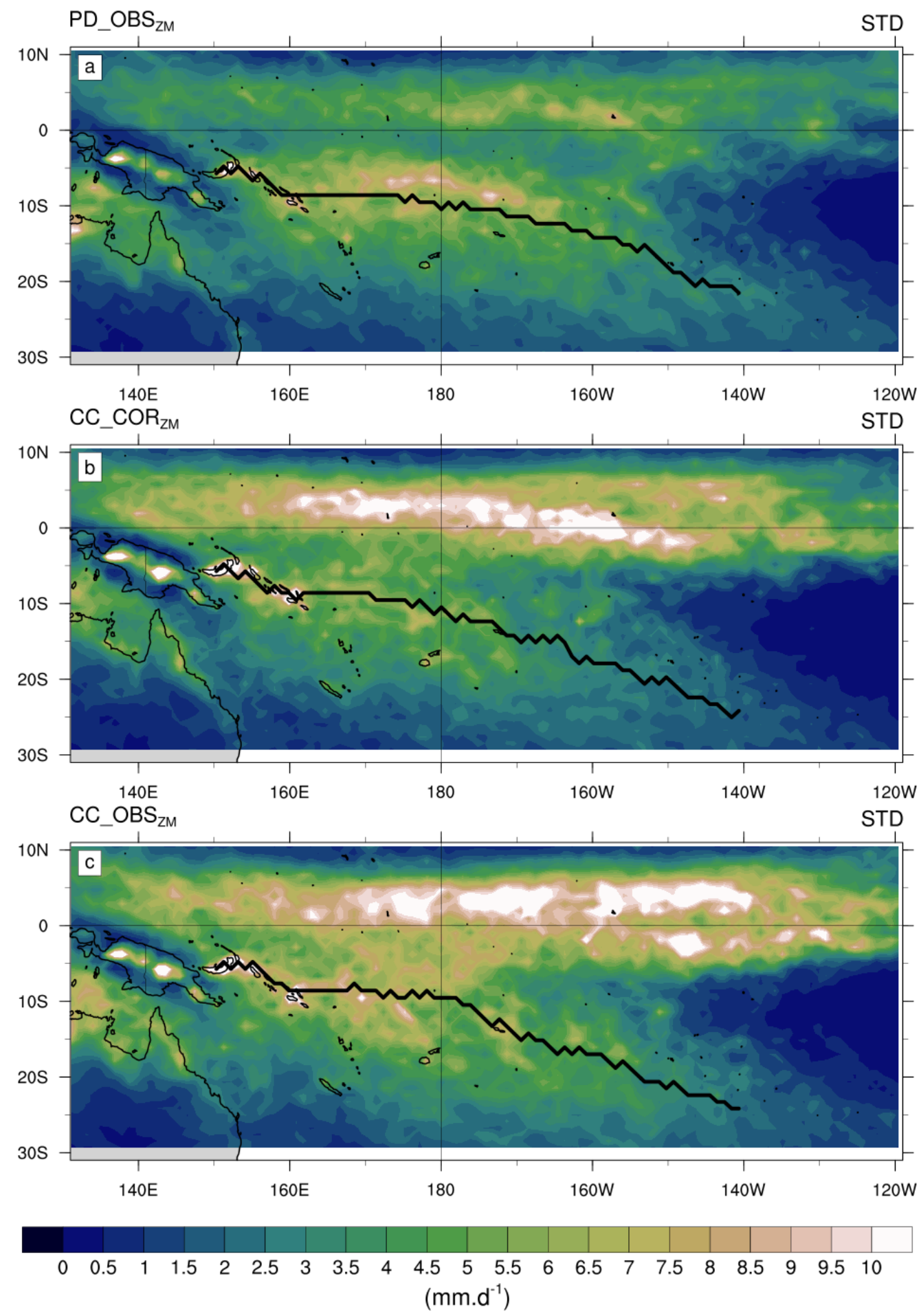

Fig. 9 Interannual standard deviation of the DJF precipitation (in mm.d $\mathrm{d}^{-1}$ ) for a) PD_OBS ${ }_{\mathrm{ZM}}$, b) $\mathrm{CC} \_\mathrm{COR}{ }_{\mathrm{ZM}}$, c) $\mathrm{CC}_{-} \mathrm{OBS}_{\mathrm{ZM}}$ simulations. The thick black lines show the mean position of SPCZ. 

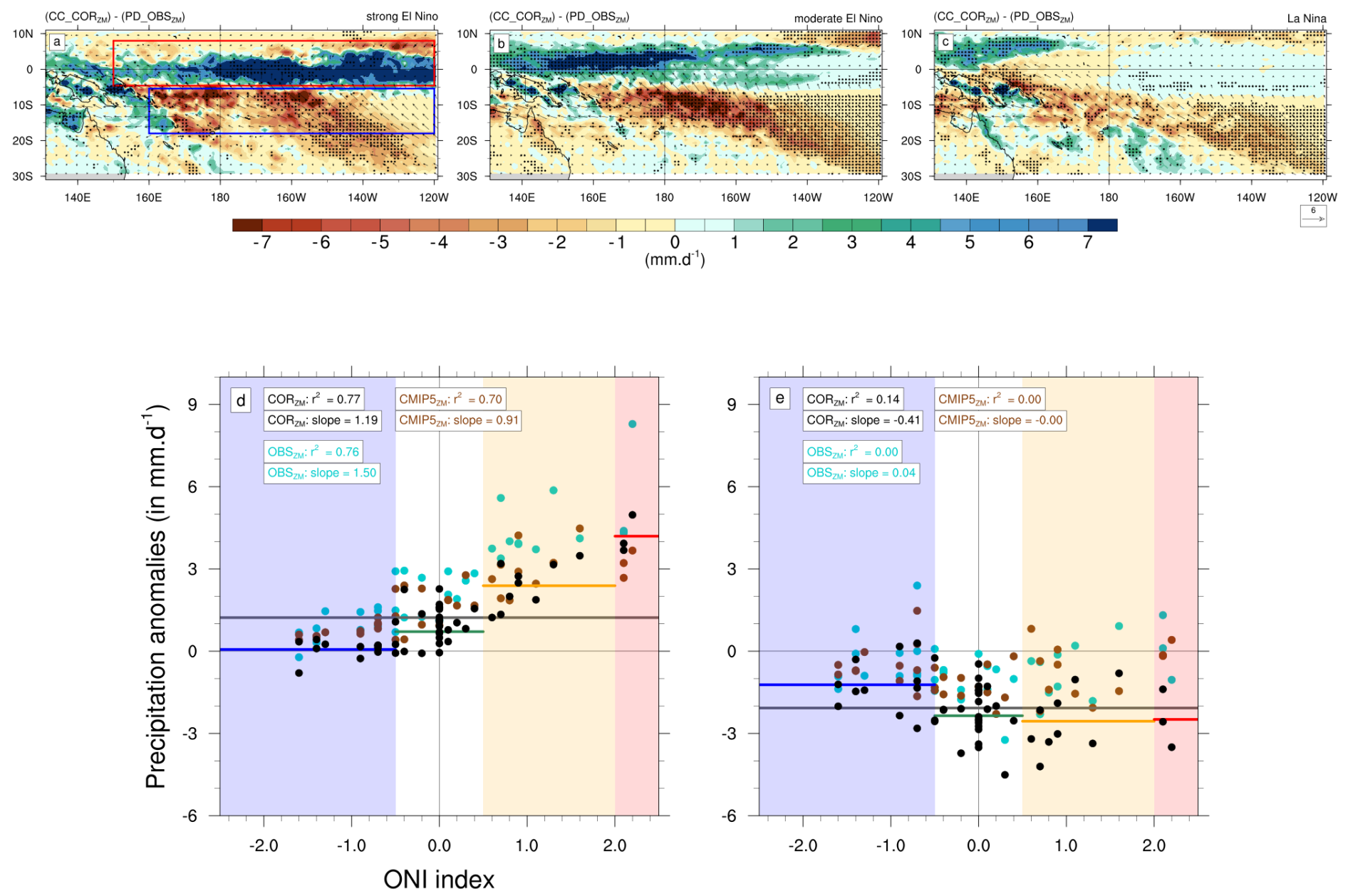

Fig. 10 Top : Projected precipitation anomalies (shading; in $\mathrm{mm} \cdot \mathrm{d}^{-1}$ ) and near surface wind (vectors; in $\mathrm{m} . \mathrm{s}^{-1}$ ) between $\mathrm{CC}_{-} \mathrm{COR}_{\mathrm{ZM}}$ and PD_OBS ${ }_{\mathrm{ZM}}$ for each ENSO mode, a) strong El Nino, b) moderate El Nino, c) La Nina. Regions where the statistical test on the mean is significant at $90 \%$ are stippled. Bottom : Scatter plot of the projected DJF precipitation anomalies as a function of ONI index for d) Equatorial box $\left[150^{\circ} \mathrm{E}-240^{\circ} \mathrm{E} ; 5^{\circ} \mathrm{S}-8^{\circ} \mathrm{N}\right]$ (red box on panel a), e) South box $\left[160^{\circ} \mathrm{E}-240^{\circ} \mathrm{E} ; 18^{\circ} \mathrm{S}-5^{\circ} \mathrm{N}\right]$ (blue box on panel a). The $\mathrm{COR}_{\mathrm{ZM}}$ experiment is represent by the black dots, the $\mathrm{OBS}_{\mathrm{ZM}}$ experiment by the cyan dots, and CMIP5 ${ }_{\mathrm{ZM}}$ experiment by the brown dots.

The gray horizontal line indicates the mean value of the precipitation change. Shadings denote ONI values of moderate El Niño (yellow), strong El Niño (red) and La Nina (blue) events, and colored horizontal lines denote the composite values of the precipitation change (green for neutral years). The slope of the linear regression and the regression coefficient $\left(\mathrm{r}^{2}\right)$ are noted in the top box for the 3 set experiments, $\mathrm{COR}_{\mathrm{zM}}$ (black), $\mathrm{OBS}_{\mathrm{ZM}}$ (cyan), $\mathrm{CMIP}_{\mathrm{zM}}$ (brown). 

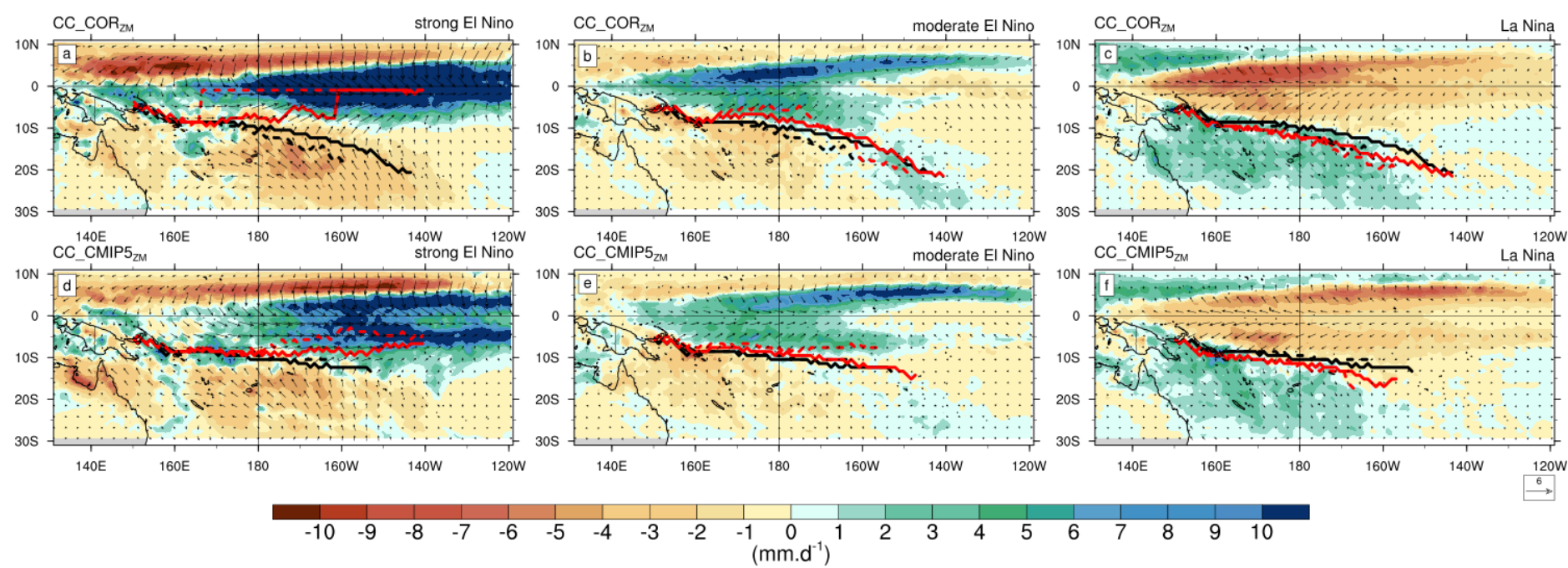

Fig. 11 Top : DJF climatology of precipitation anomalies (shading; in $\mathrm{mm} \cdot \mathrm{d}^{-1}$ ) and near surface wind (vectors; in $\mathrm{m}^{-\mathrm{s}^{-1}}$ ) for CC_COR $\mathrm{ZM}_{\text {(top), } \mathrm{CC}_{-} \mathrm{CMIP5}}$ (bottom) simulation for each ENSO mode ; strong El Nino (left), moderate El Nino (center), La Nina (right). On each panel, the black thick (dashed) line displays the mean position of SPCZ in the present (future) simulation, the red thick (dashed) lines are the ENSO-based composite SPCZ position in the present (future) simulation. 


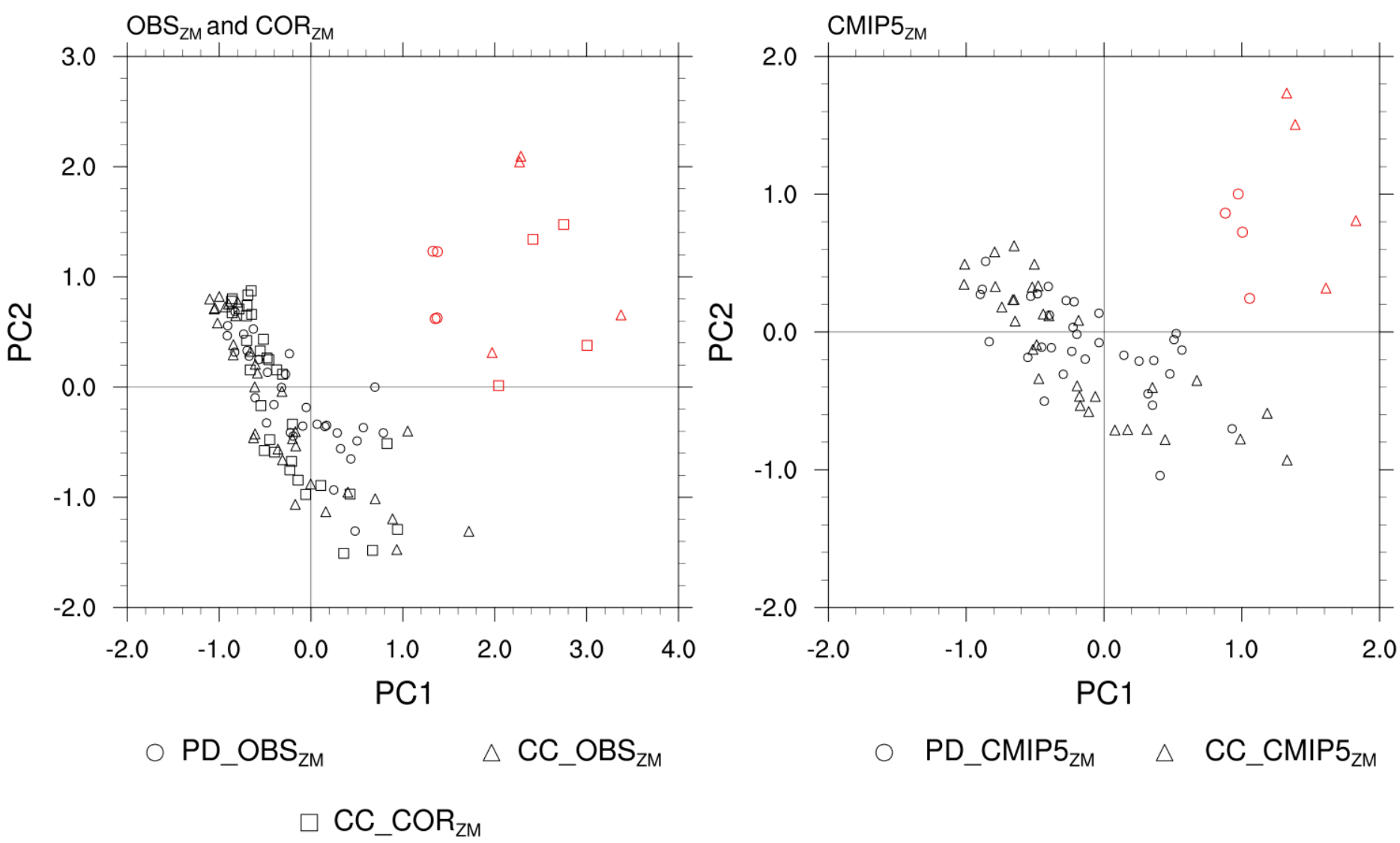

Fig. 12 The relationship between the associated two principal component time series for a) $\mathrm{OBS}_{\mathrm{ZM}}$ and $\mathrm{COR}_{\mathrm{ZM}}$ experiment, b) CMIP5 $5_{\mathrm{zM}}$ experiment. A zonal SPCZ event (red symbols) is defined as when the first principal component is greater than one standard deviation, and when the second principal component is greater than zero. The circles represent the present-day simulations, triangles and squares the climate change simulations. 

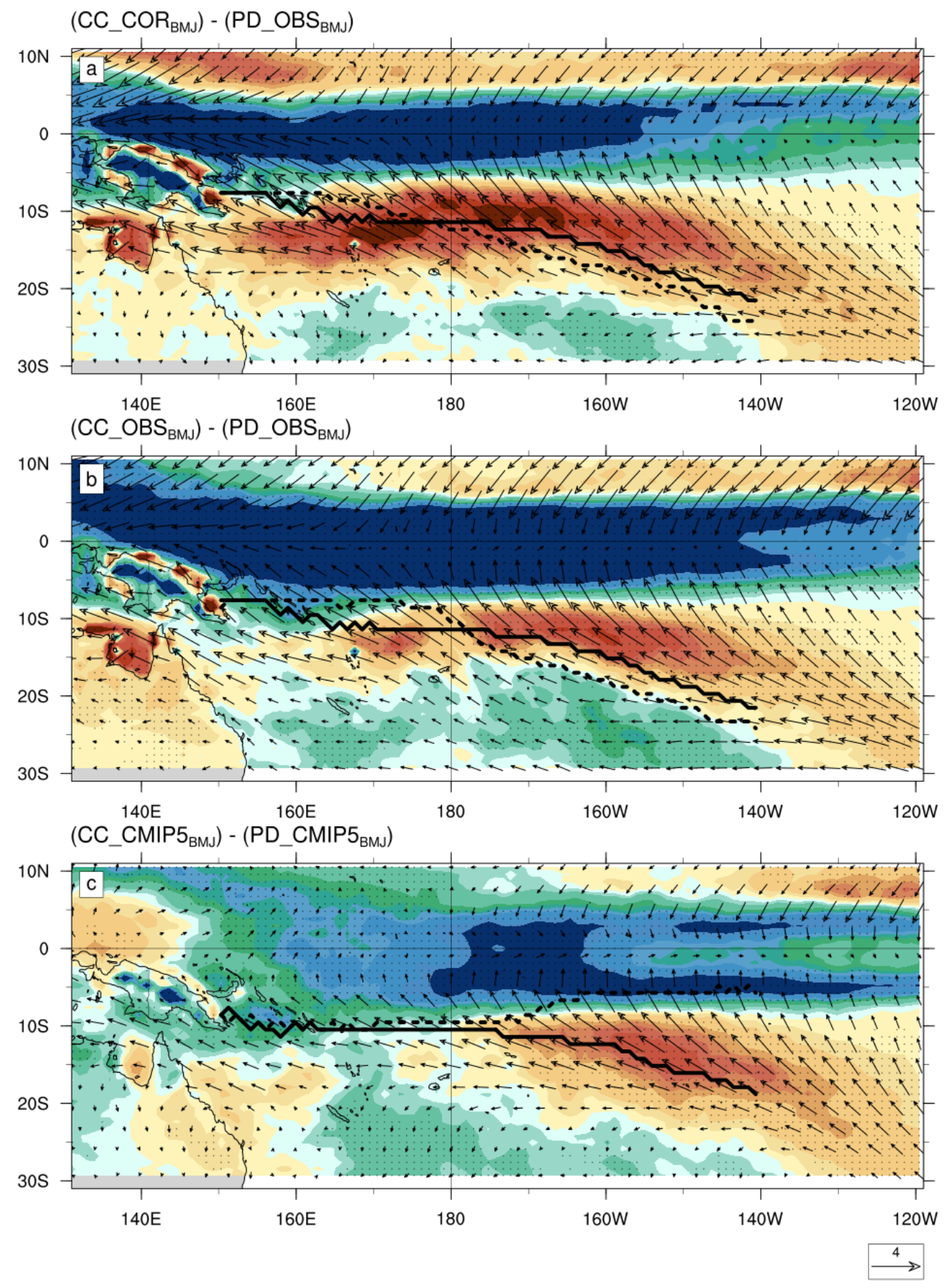

$\begin{array}{ccccccccccccccccccccc}-5 & -4.5 & -4 & -3.5 & -3 & -2.5 & -2 & -1.5 & -1 & -0.5 & 0 & 0.5 & 1 & 1.5 & 2 & 2.5 & 3 & 3.5 & 4 & 4.5 & 5 \\ \left(\mathrm{~mm}^{-1}\right) & & & & & & \end{array}$

Fig. 13 DJF precipitation changes (in $\mathrm{mm} \cdot \mathrm{day}^{-1}$ ) and near surface wind changes (in $\mathrm{m} \cdot \mathrm{s}^{-1}$ ) between futur and present ; a) $\mathrm{COR}_{\mathrm{BMJ}}$, b) $\mathrm{OBS}_{\mathrm{BMJ}}$, c) $\mathrm{CMIP5}_{\mathrm{BMJ}}$. Regions where the statistical test on the mean is significant at $95 \%$ are stippled. 

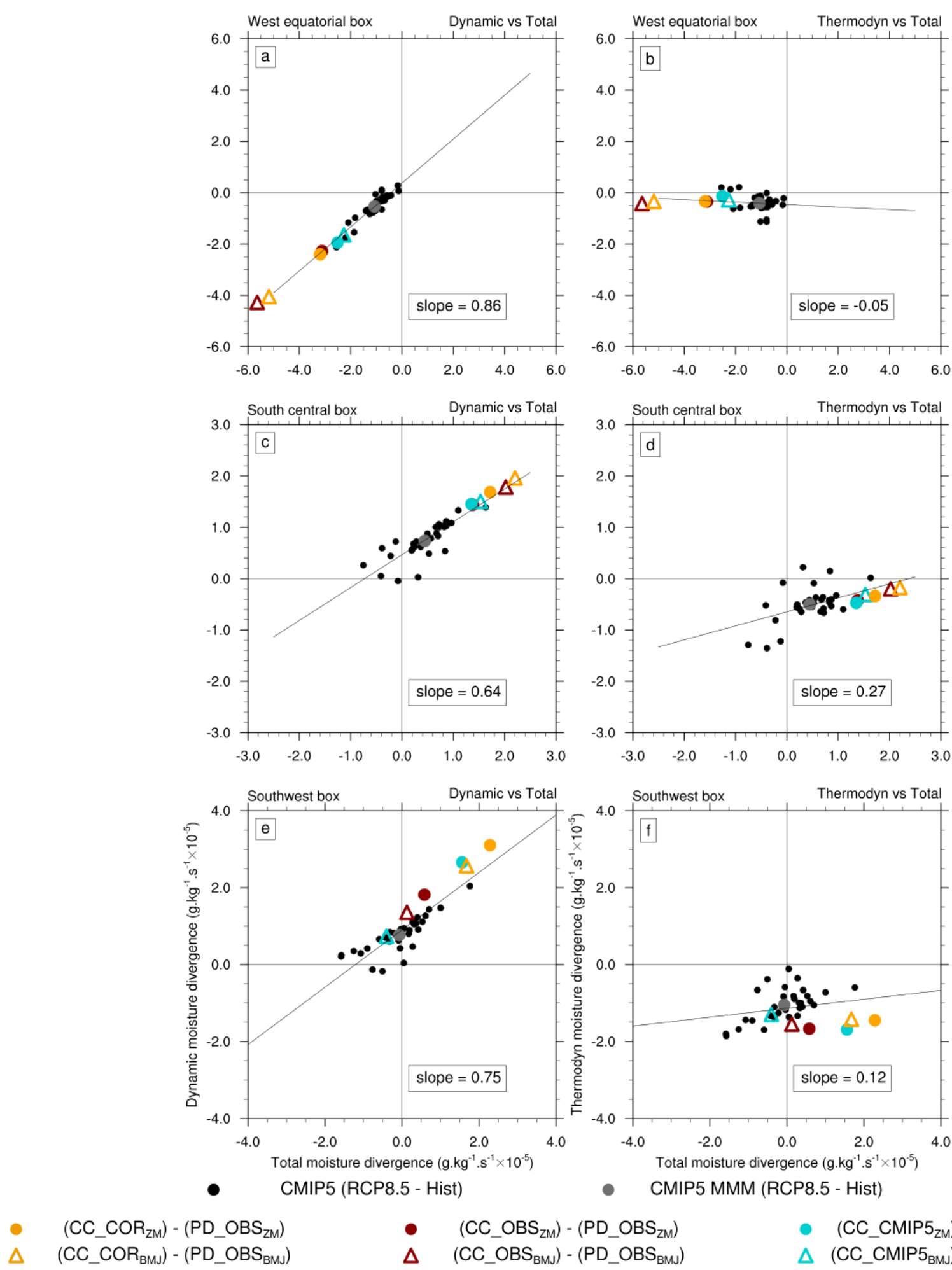

- $\left(\right.$ CC_OBS $\left.\mathrm{ZMM}_{\mathrm{M}}\right)-\left(\mathrm{PD} \mathrm{OBS}_{\mathrm{ZM}}\right)$

- $\left(\right.$ CC_CMIP5 $\left.5_{\mathrm{ZM}}\right)-\left(\right.$ PD_CMIP5 $\left.5_{\mathrm{ZM}}\right)$

$\triangle\left(\right.$ CC_CMIP5 $\left.5_{\text {BMJ }}\right)-\left(P D \_C M I P 5_{\text {BMJ }}\right)$

Fig. 14 Scatter plot showing the relations between the moisture divergence change (future - present ; in $\mathrm{g} \cdot \mathrm{kg}^{-1} \cdot \mathrm{s}^{-1} \times 10^{-5}$ ) and its dynamical (left) or thermodynamical (right) effects in the CMIP5 models ensemble (RCP8.5 - historical; black, with the CMIP5 MMM in grey), the $\left(\mathrm{CC}_{-} \mathrm{COR}_{\mathrm{ZM}}\right)_{-}^{-}$ $\left(\mathrm{PD}_{-} \mathrm{OBS}_{\mathrm{ZM}}\right)$ (orange dot), the $\left(\mathrm{CC}_{-} \mathrm{OBS}_{\mathrm{ZM}}\right)-\left(\mathrm{PD}_{-} \mathrm{OBS} \mathrm{ZM}_{\mathrm{Z}}\right)$ (red dot) and $\left(\mathrm{CC} \_\mathrm{CMIP5}{ }_{\mathrm{ZM}}\right)-$ $\left(\mathrm{PD}_{-} \mathrm{CMIP5}_{\mathrm{ZM}}\right)$ (cyan dot) simulations, and the $\left(\mathrm{CC}_{-} \mathrm{COR}_{\mathrm{BMJ}}\right)-\left(\mathrm{PD}_{-} \mathrm{OBS}_{\mathrm{BMJ}}\right)$ (orange triangle), the $\left(\mathrm{CC}_{-} \mathrm{OBS}_{\mathrm{BMJ}}\right)-\left({\mathrm{PD} \_O B S_{\mathrm{BMJ}}}\right)$ (red triangle) and $\left(\mathrm{CC}_{-} \mathrm{CMIP}_{\mathrm{BMJ}}\right)-\left(\mathrm{PD}_{-} \mathrm{CMIP}_{\mathrm{BMJ}}\right)$ (cyan triangle) simulations. The relations are evaluated in three different boxes shown on Figure 6a: the equatorial box $\left[150^{\circ} \mathrm{E}-200^{\circ} \mathrm{E} ; 5^{\circ} \mathrm{S}-7^{\circ} \mathrm{N}\right]$ (top), South central box $\left[200^{\circ} \mathrm{E}-240^{\circ} \mathrm{E} ; 25^{\circ} \mathrm{S}-5^{\circ} \mathrm{S}\right]$ (middle), and Southwest box $\left[160^{\circ} \mathrm{E}-200^{\circ} \mathrm{E} ; 15^{\circ} \mathrm{S}-5^{\circ} \mathrm{S}\right]$ (bottom). The slope of the linear regression and the standard error of the regression coefficient ( $\mathrm{r}$ std) are noted in the bottom right-hand box. 
Table 1 : Physics parametrization selected in the ZM and BMJ model configurations

\begin{tabular}{|c|c|c|}
\hline Configuration & Physical models & Parametrization \\
\hline
\end{tabular}

Land-surface model

Oceanic surface

layer

Microphysic

(1) ZM

PBL and shallow

convection

Deep convection

Longwave and

shortwave

radiation
Unified Noah

Monin-Obukhov scheme

Purdue Lin (one moment)

UW CAM5 moist turbulence with explicit entrainment at the top of the PBL and shallow convection, unified parameterization

Zhang-McFarlane

CAM3 scheme
Chen and Dudhia (2001)

Jiménez et al. (2012)

Lin et al. (1983)

Bretherton and Park (2009)

Park and Bretherton (2009)

Zhang and McFarlane (1995)

Community Atmospheric model Version 3 (Collins et al., 2004). (With cloud fraction computed from Xu and Randall (1996))

Land-surface model

Unified Noah

Chen and Dudhia (2001)

Oceanic surface layer

Microphysic

(2) BMJ

PBL

Deep convection

Longwave and

Monin-Obukhov scheme

WRF

singlemoment threeclass microphysics scheme

Yonsei University scheme

Noh et al. 2003

Betts-Miller-Janjic

Janjic 1994

Rapid Radiation Iacono et al. 2008

Jiménez et al. (2012)

Hong et al. 2004 GCMs 
Table 2 : List of variables concerned by the delta methodology

\begin{tabular}{lcc}
\hline Variables & $\begin{array}{c}\text { Variable } \\
\text { dimensions }\end{array}$ & Unity \\
\hline Specific humidity & $3 \mathrm{D}$ & $\mathrm{kg} \cdot \mathrm{kg}^{-1}$ \\
Temperature & $3 \mathrm{D}$ & $\mathrm{K}$ \\
U-component of wind & $3 \mathrm{D}$ & $\mathrm{m} / \mathrm{s}$ \\
V-component of wind & $3 \mathrm{D}$ & $\mathrm{m} \cdot \mathrm{s}^{-1}$ \\
Geopotential height & $3 \mathrm{D}$ & $\mathrm{m}$ \\
Relative humidity at 2m & 2D & $\mathrm{Percent}$ \\
U-component of wind at 10m & 2D & $\mathrm{m} \cdot \mathrm{s}^{-1}$ \\
V-com ponent of wind at 10m & 2D & $\mathrm{m} \cdot \mathrm{s}^{-1}$ \\
Temperature of surface at $2 \mathrm{~m}$ & 2D & $\mathrm{K}$ \\
Pressure at surface & 2D & $\mathrm{Pa}$ \\
SST/Land Skin Temperature & 2D & $\mathrm{K}$ \\
at the Surface & & $\mathrm{Pa}$ \\
Sea Level Pressure & $2 \mathrm{D}$ & \\
\hline
\end{tabular}


Table 3 : List and description of the different simulations

\begin{tabular}{|c|c|c|c|c|}
\hline Experiment name & Physics & Period & SST \& BDY & Scenario \\
\hline PD_OBS ${ }_{\mathrm{zM}}$ & Table $1(1)$ & Jan 1980 - Jun 2016 & NCEP2 & Historical \\
\hline PD_OBS ${ }_{\text {вм }}$ & Table 1 (2) & Jan 1980 - Jun 2016 & NCEP2 & Historical \\
\hline PD_CMIP5 ${ }_{Z M}$ & Table 1 (1) & Jan 1980 - Jun 2016 & $\begin{array}{c}\text { NCEP } 2+\text { CMIP5 } \\
\text { MMM bias }\end{array}$ & Historical \\
\hline PD_CMIP5 $5_{\text {ВMJ }}$ & Table 1 (2) & Jan 1980 - Jun 2016 & $\begin{array}{c}\text { NCEP2 + CMIP5 } \\
\text { MMM bias }\end{array}$ & Historical \\
\hline $\mathrm{CC}_{-} \mathrm{COR}_{\mathrm{zM}}$ & Table 1 (1) & Jan 2072 - Jun 2108 & $\begin{array}{c}\text { NCEP2 }+ \\
\text { corrected CMIP5 } \\
\text { MMM anomaly }\end{array}$ & RCP8.5 \\
\hline CC_COR & Table 1 (2) & Jan 2072 - Jun 2108 & $\begin{array}{c}\text { NCEP2 }+ \\
\text { corrected CMIP5 } \\
\text { MMM anomaly }\end{array}$ & RCP8.5 \\
\hline $\mathrm{CC}_{-} \mathrm{OBS}_{\mathrm{zM}}$ & Table 1 (1) & Jan 2072 - Jun 2108 & $\begin{array}{l}\text { NCEP2 + CMIP5 } \\
\text { MMM anomaly }\end{array}$ & RCP8.5 \\
\hline $\mathrm{CC}_{-} \mathrm{OBS}_{\text {ВмJ }}$ & Table 1 (2) & Jan 2072 - Jun 2108 & $\begin{array}{l}\text { NCEP2 + CMIP5 } \\
\text { MMM anomaly }\end{array}$ & RCP8.5 \\
\hline CC_CMIP5 $5_{z M}$ & Table 1 (1) & Jan 2072 - Jun 2108 & $\begin{array}{l}\text { NCEP2 + CMIP5 } \\
\text { MMM bias + CMIP5 } \\
\text { MMM anomaly }\end{array}$ & RCP8.5 \\
\hline CC_CMIP5 $5_{\mathrm{BMJ}}$ & Table 1 (2) & Jan 2072 - Jun 2108 & $\begin{array}{l}\text { NCEP2 + CMIP5 } \\
\text { MMM bias + CMIP5 } \\
\text { MMM anomaly }\end{array}$ & RCP8.5 \\
\hline
\end{tabular}

